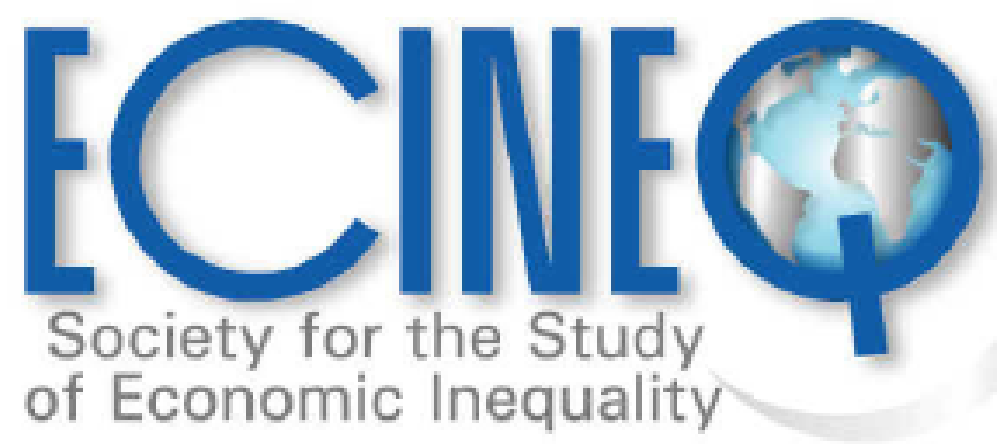

Working Paper Series

Poverty in the COVID-19 Era: Real Time Data Analysis on Five European Countries

Giorgia Menta 


\title{
ECINEQ 2021568
}

2021 January

www.ecineq.org

\section{Poverty in the COVID-19 Era: Real Time Data Analysis on Five European Countries}

\author{
Giorgia Menta \\ University of Luxembourg
}

\begin{abstract}
Using real-time data from the University of Luxembourg's COME-HERE nationally representative panel survey, covering more than 8,000 individuals across France, Germany, Italy, Spain, and Sweden, I investigate how income distributions and poverty rates havechanged from January to September 2020. I find that poverty rates increased on average in allcountries from January to May and partially recovered in September. The increase in povertyis heterogeneous across countries, with Italy being the most affected and France the least;within countries, COVID-19 contributed to exacerbating poverty differences across regions inltaly and Spain. With a set of poverty measures from the Foster-Greer-Thorbecke family, I thenexplore the role of individual characteristics in shaping different poverty profiles acrosscountries. Results suggest that poverty increased disproportionately more for youngindividuals, women, and respondents who had a job in January 2020 - with different intensityacross countries.
\end{abstract}

Keyword: COVID-19, Poverty, TIP, Europe, Headcount ratio

JEL Cassification: 114, I18, I32 


\title{
Poverty in the COVID-19 Era:
}

\section{Real Time Data Analysis on Five European Countries*}

\author{
GiORGIA MENTA \\ University of Luxembourg \\ giorgia.menta@uni.lu
}

This version: December 2020

\begin{abstract}
Using real-time data from the University of Luxembourg's COME-HERE nationally representative panel survey, covering more than 8,000 individuals across France, Germany, Italy, Spain, and Sweden, I investigate how income distributions and poverty rates have changed from January to September 2020. I find that poverty rates increased on average in all countries from January to May and partially recovered in September. The increase in poverty is heterogeneous across countries, with Italy being the most affected and France the least; within countries, COVID-19 contributed to exacerbating poverty differences across regions in Italy and Spain. With a set of poverty measures from the Foster-Greer-Thorbecke family, I then explore the role of individual characteristics in shaping different poverty profiles across countries. Results suggest that poverty increased disproportionately more for young individuals, women, and respondents who had a job in January 2020 - with different intensity across countries.
\end{abstract}

Keywords: COVID-19, Poverty, TIP, Europe, Headcount ratio

JEL Classification Codes: I14, I18, I32

*I would like to thank Conchita D'Ambrosio and Anthony Lepinteur for their useful comments. Financial support from the André Losch Fondation, Art2Cure, Cargolux, Fonds National de la Recherche Luxembourg (Grants 14840950 - COME-HERE, and 10949242) is gratefully acknowledged. 


\section{Introduction}

The COVID-19 pandemic represents an on-going challenge to health systems and economies all over the world. Since its first diffusion in early 2020, the Governments of countries most heavily hit by the pandemic have had to design and implement carefully balanced sets of measures and restrictions, with the objective of limiting the diffusion of the virus, while ensuring at least a certain degree of continuity in their countries' economic activity. With economies GDP's plummeting, space has been given in parallel to recovery schemes, both at the national and transnational level. An increasing number of papers have documented some of the socio-economic implications of COVID-19, many focussing on its adverse labour market consequences (Adams-Prassl et al., 2020; Beland et al., 2020; Jones et al., 2020; Jordà et al., 2020; Stephany et al., 2020), as well as well as its effects in exacerbating pre-existing inequalities (Adams-Prassl et al., 2020; Ali et al., 2020; Alon et al., 2020; Blundell et al., 2020; Platt and Warwick, 2020). While worse labour market outcomes are indeed likely to affect household income and its distribution, relatively little is known on about the net distributional and poverty consequences of the combination of confinement measures, higher health hazard, and countercyclical recovery measures and their timeliness.

To the best of my knowledge, this is the first paper using individual-level longitudinal data to investigate the evolution of poverty in Europe in the COVID-19 era. The majority of the current literature on the poverty and income inequality consequences of COVID-19 relies in fact on microsimulation techniques. Using the EUROMOD microsimulation module on a set of European countries, Almeida et al. (2020) find a 3.6 to 5.9\% reduction in household income and an increase in at-risk-of-poverty rates of 1.7 percentage points (from here onwards, pp) in the presence of policy measures. Other papers have used EUROMOD to predict the poverty and inequality consequences of different lockdown scenarios: simulating individuals' potential wage losses under different lockdown intensity and length, Palomino et al. (2020) predict an 
increase of both poverty ( $3 \mathrm{pp}$ higher headcount ratio under a two-month lockdown) and wage inequality across all European countries. Zooming into the Italian module of EUROMOD, Brunori et al. (2020) predict an increase both in poverty and inequality as a result of the restrictive measures implemented between February and April 2020, and Figari and Fiorio (2020) document an increase in overall income inequality and the risk of poverty between 8 and 15 pp. Using UKMOD, Bronka et al. (2020) find that, in an absence of policy changes, a $1.2 \mathrm{pp}$ increase in the poverty rate in the UK can be attributed to the COVID-19 crisis. Simulation and calibration exercises in Li et al. (2020) predict that, in absence of policy responses, poverty rates might have doubled in Australia due to COVID-19.

Some exceptions to these simulation exercises on poverty are Brewer and Gardiner (2020), Delaporte et al. (2020), and Han et al. (2020). Using UK real-time data for 6,000 respondents of the Resolution Foundation's Coronavirus survey, Brewer and Gardiner (2020) find that 33\% of respondents reported a fall in household income between Janaury and May 2020 - evenly distributed across the working-age income distribution. Delaporte et al. (2020) instead look at Latin-American and Caribbean countries, using national household survey data harmonised by the Inter-American Development Bank. They find on average a $0.6 \mathrm{pp}$ increase in poverty rates, the largest one being in Peru (1.4 pp). Lastly, Han et al. (2020) use the basic monthly US Current Population Survey (CPS) to show that poverty in the US fell between February and June 2020, as a result of targeted income-support government policies. However, subsequent waves of the CPS show an increase in poverty rates, in parallel with the higher number of COVID-19 cases confirmed in the US since the end of the summer. ${ }^{1}$

I here investigate the evolution of poverty during the first waves of COVID-19 across five European countries, using novel real time data from the COME-HERE longitudinal survey collected by the University of Luxembourg. The survey is nationally representative and follows

\footnotetext{
${ }^{1}$ Poverty figures are available at: http://povertymeasurement.org/covid-19-poverty-dashboard/.
} 
over 8,000 individuals across France, Germany, Italy, Spain, and Sweden over time (from April 2020, with retrospective information on the pre-lockdown period, up to November 2020). Using poverty measures from the Foster-Greer-Thorbecke family (Foster et al., 1984) and TIP curves, together with relative at-risk-of-poverty lines anchored to pre-COVID income distributions, I find that poverty increased ubiquitously across the five countries in analysis during May 2020 with respect to baseline levels measured in January, to almost go back to its initial levels by September. While on average at-risk-of-poverty rates increased by 4 pp from January to May, results are heterogenous by country, with Italian residents being the most affected from the COVID-19 crisis ( 9 pp increase) and French the least ( 1 pp increase). Recovery patterns from May to September also differ geographically, with only France and Spain experiencing a full recovery and displaying the same poverty figures in January and September. Additionally, I find evidence that the COVID-19 crisis contributed to exacerbating pre-existing geographical differences in poverty rates within the Italian and Spanish territories.

Heterogeneity analysis based on individual characteristics further identifies which categories experienced the higher risk of falling into poverty as a consequence of COVID in May 2020. Poverty measures for individuals below the median age increased more than those of older individuals everywhere; in Spain and Italy, women were disproportionately more vulnerable than men to higher poverty levels. Education and employment, while keeping individuals from experiencing low poverty levels in absolute terms, do not appear to have played a protective role against the relative increase in poverty between January and May: individuals with at least a secondary education degree, as well as those who had a job in January 2020, experienced relatively larger increases in poverty with respect to their counterparts - the educational and employment poverty gaps narrowing as a consequence.

This paper contributes to the understanding of the evolution of poverty during COVID-19 across different European countries with the use of recent real-time panel data. It further sheds 
light on the role of individual characteristics in exacerbating or hindering the risk of poverty, by identifying population segments with higher vulnerability to the COVID-19 crisis.

The remainder of the paper is organised as follows: Section 2 describes the COME-HERE survey and the method used to compute poverty and build the analysis sample. Section 3 presents the main results, together with heterogeneity analysis. Sensitivity analysis is performed in Section 4. Lastly, Section 5 concludes.

\section{Data and Methodology}

\subsection{The COME-HERE Longitudinal Survey}

I here use data from the first four waves of the COME-HERE (COVID-19, MEntal HEalth, REsilience and Self-regulation) longitudinal survey, conducted by the University of Luxembourg and administered via Qualtrics. ${ }^{2}$ The survey, aimed at understanding the psychological effects COVID-19 and social distancing measures across Europe, was administered to nationally representative samples of individuals in France, Germany, Italy, Spain, and Sweden for the first time between the end of April and the beginning of May $2020 .^{3}$ The same pool of individuals was recontacted three additional times in June, August, and end of November/early December 2020. About 8,000 people responded to the first survey wave, evenly distributed across the five different countries. ${ }^{4} 42 \%$ of these respondents were observed in all the next waves as well (with an additional $14 \%$ only missing from wave 2 ); only $17 \%$ of respondents in the first wave did not participate to at least another interview.

The COME-HERE survey includes a wide range of questions, spanning from socioeconomic and demographic characteristics to a variety of measures of mental health, resilience, and social support. In order to investigate the risk of falling into poverty and the protective role

\footnotetext{
${ }^{2}$ Ethics approval was granted by the Ethics Review Panel of the University of Luxembourg.

${ }^{3}$ Sample representativeness was assured in terms of age, gender, and region of residence.

${ }^{4}$ Each country accounting for around $21 \%$ of the observations, with the exception of Sweden which makes up $15 \%$ of the first-wave sample.
} 
played by socio-demographic factors such as age, gender, and education, I here focus on the economic and demographic dimensions measured by the survey.

In all waves, individuals in the COME-HERE survey were asked, "taking all sources together and all household members living with you", to recall their net monthly household income (after taxes and transfers) from a few months earlier. In wave 1, which took place between April and May, respondents reported their household income from January 2020; in wave 2, taking place in June, respondents reported their income from April 2020; in wave 3, taking place in August, respondents reported their income from May 2020; lastly, in wave 4, which took place between November and December, respondents were asked about their income in September 2020. Responses were bounded to the seven following income bands: 01250 Euros; 1250-2000 Euros; 2000-4000 Euros; 4000-6000 Euros; 6000-8000 Euros; 800012500 Euros; >12500 Euros. ${ }^{5}$ A "prefer not to say" option was available as an alternative answer.

In order to maximise the observational period of income in the survey and have equally spaced interview windows, I here focus on waves 1,3 , and 4 of the COME-HERE questionnaire. In particular, from wave 1 I derive information on household income in January 2020 and a set of baseline characteristics which are only observed in wave 1 (i.e. age, gender, education, country of residence). From wave 3, I take the reported household income bands referring to the period of May 2020, and from wave 4 household income bands for September 2020.

\subsection{Methodology}

The household income reported by COME-HERE respondents, as described above, is the starting point to build the measures of poverty used throughout the rest of the paper. As I here

\footnotetext{
${ }^{5}$ Income bands in Sweden were expressed in Swedish crowns (SEK) as follows: 0 - 12,960 SEK; 12,960 - 20,736 SEK; 20,736 - 41,472 SEK; 41,472 - 62,208 SEK; 62,208 - 82,942 SEK; 82,942 - 1,295,97 SEK; >1,295,97 SEK.
} 
investigate five European economies, I adopt Eurostat's notion of relative poverty lines, computed as $60 \%$ of a country's median equivalised household income, below which individuals are considered to be at-risk-of-poverty. As in Almeida et al. (2020), in order to avoid confounding in income distributions and relative poverty due to the advancement of the pandemic, I only use pre-COVID-19 income distributions for the definitions of poverty lines in each country (i.e. the January 2020 income distributions from the COME-HERE survey for the main analysis, and then the 2019 EU-SILC wave's income distributions for sensitivity analysis). Comparing respondents' equivalised household income with their country's anchored relative poverty line, I then compute a set of poverty measures of the Foster-GreerThorbecke class (Foster et al., 1984), similary to Delaporte et al. (2020).

In particular, let $z$ denote a country's relative poverty line and $i=1, \ldots, N$ be that country's population ordered by income, $y_{1} \leq y_{2} \leq \cdots y_{p}<y_{p+1} \leq \cdots \leq y_{N}$, with $y_{p} \leq z<y_{p+1}$ and where income has been appropriately equivalised to take into account economies of scale across members of the same household. Therefore, $P=\left\{y_{1}, y_{2}, \ldots, y_{p}\right\}$ is the set of poor individuals, which has size $p$. Let $g_{y i}$ be the normalised poverty gap associated with income $y_{i}$, defined as $g_{y i}:=\max \left\{\left(z-y_{i}\right) / z ; 0\right\}$. The set of indicators of the Foster-Greer-Thorbecke (FGT) family (Foster et al., 1984) can then be defined as follows:

$$
F G T(\alpha)=\frac{1}{N} \sum_{i=1}^{N} g_{y i}{ }^{\alpha}, \alpha \geq 0
$$

If $\alpha=0$ then the $F G T$ indicator is equal to the headcount ratio $p / N$, which is informative on the incidence of poverty in a population. For $\alpha=1$, then the indicator is equal to the poverty gap ratio, which can be interpreted as the income per capita required to bring every poor at the poverty line and is a measure of poverty intensity. The case proposed by Foster et al. (1984) was using $\alpha=2$ : here the indicator is referred to as the squared poverty gap, measuring the severity of poverty. Together, these three versions of the index for $\alpha=\{0,1,2\}$ capture the three ' $\mathrm{i}$ 's of poverty (TIP): incidence, intensity, and inequality. The three dimensions can all 
be appreciated graphically using TIP curves, which plot cumulative normalised poverty gaps per capita against cumulative population shares (Jenkins and Lambert, 1997). One advantage of using TIP curves, other than the ease of comparison across different income distributions, is that they can be ranked in terms of poverty dominance: given the same poverty line $z$, if the $T I P$ curve for income distribution $x, \operatorname{TIP}(x ; z)$, is such that $\operatorname{TIP}(x ; z) \geq T I P(y ; z)$, and the inequality is strict for at least some points, then income distribution $x$ poverty-dominates income distribution $y$. TIP dominance is equivalent to a unanimous poverty ordering given not only by all $F G T$ indices with $\alpha \geq 1$, but also other by other poverty indices such as the ones in Chakravarty (1983), Shorrocks (1995), and Watts (1968).

In order to build national distributions of equivalised household income in the COMEHERE survey, I take the mid-point of the reported household's banded income for January, May, and September 2020 (as in Clark and Senik, 2010), and divide it by the square root of household size. As reported household sizes are on average larger than official national statistics, I perform some adjustments in order to rule out cohabitation of individuals constituting different households (as it is often the case for young students/workers sharing an apartment with other people without pooling economic resources). In particular, based on their relationship status (single vs in a cohabiting relationship), I attribute household size of one or two to the 534 employed respondents in the sample below 40 years old, with no children, who report having a household size larger than one or two. ${ }^{6}$ Additionally, in order to avoid an overestimation of poverty for individuals whose household income is in the lowest income band (where the mid-point is automatically below any relative poverty threshold), I treat the 41 individuals living alone, whose employment status is "retired" and who report being in the lowest income band, as non-poor.

\footnotetext{
${ }^{6}$ Section 4 shows that results are not sensitive to the introduction of these restrictions on household size (if anything, poverty figures are underestimated when using them).
} 
The final analysis sample is given by individuals with no missing values for income, household size, and a set of time-invariant individual characteristics described in Table 1. In order to avoid the risk of changes in poverty measures over time being driven by non-random attrition between wave 1 and 4, I further restrict the analysis sample to a balanced panel of 4,078 individuals. Descriptive statistics for the estimation sample in Table 1 show that, on average, income in the sample fell between January and May, but it slightly raised again in September. Similarly, average at-risk-of-poverty rates increased by 4 pp between January and May, to fall again by $3 \mathrm{pp}$ by September. Of the analysis sample, $23 \%$ of respondents reside in France, 20\% in Germany, 26\% in Italy, 25\% in Spain, and 6\% in Sweden.

Sample selection statistics presented in Table A1 compare individuals in the estimation sample to the remaining 3,985 respondents who are observed in wave 1. Figures in Table A1 suggest that attrition is indeed non-random: only $18 \%$ of respondents in the analysis sample are poor in January 2020 , against $24 \%$ of all others who are observed in wave 1 . Additionally, the analysis sample is made up by individuals who are on average six years older, as well as more likely to be men, in a cohabiting relationship, and with a tertiary education degree. Selection is in place also at the country of residence level: individuals in the sample are $16 \mathrm{pp}$ less likely to be from Sweden, with larger shares of Italian, Spanish, and French residents. While geographic selection might be problematic when interpreting results for Sweden, due to the small number of individuals kept in the sample, selection based on other observable characteristics is less worrying: as individuals who are less likely to be poor are overrepresented in the analysis sample, results could be suffering from an attenuation bias and, as such, should be interpreted as a lower bounds.

With the exception of Table 2, results presented in the paper are based on equivalised disposable income, converted in 2019 US dollars using purchasing power parity (PPP). Furthermore, results are all weighted for household size - unless otherwise specified. 


\section{Results}

\subsection{Main Results}

Before moving on to the main analysis, I first check how reliable the January 2020 at-riskof-poverty (ARP) rates from the COME-HERE survey are as compared to the official Eurostat ARP statistics for year 2019. ${ }^{7}$ Column 1 of Table 2 reports the Eurostat ARP rates for the five countries in the analysis, computed as the share of individuals whose equivalised disposable income is below their country's relative poverty lines, and based on EU-SILC data. Relative poverty lines are defined as $60 \%$ of the national median equivalised disposable monthly income and are reported in column 2 (expressed in euros per month). ${ }^{8}$ Using the same definition of ARP rates and poverty lines, but based on the COME-HERE equivalised disposable monthly income distributions, columns 3, and 4 report, respectively, the ARP rates and national relative poverty lines for the analysis sample, in each of the five countries of the analysis. Due to the discrete nature of the reported income in the COME-HERE survey, equivalised household income only takes a fixed set of values, and so do the poverty lines reported in column 4 . Nevertheless, poverty lines in column 4 appear to mirror quite closely the ones based on EUSILC reported in column 2, with absolute differences ranging from only one euro in the case of Sweden, to a maximum of 136.4 euros for Germany. Similarly, ARP rates in column 3 are on average only $0.4 \mathrm{pp}$ lower than the ones in column 1 , suggesting that poverty rates in the COME-HERE survey in January 2020 closely mirror representative national statistics from Eurostat in 2019. In the sensitivity analysis (section 4), I use the Eurostat's poverty lines in column 2 of Table 2, instead of the ones in column 4, in order to assess to what extent results in the paper are sensitive to the within-sample choice of national relative poverty lines.

\footnotetext{
${ }^{7}$ Eurostat figures available at: https:/ec.europa.eu/eurostat/databrowser/view/tespm010/default/table?lang=en. ${ }^{8}$ The equivalence scale used for Eurostat's ARP statistics is the OECD-modified scale. Eurostat poverty lines for year 2019 can be accessed here: http://appsso.eurostat.ec.europa.eu/nui/submitViewTableAction.do.
} 
The distributions of equivalised disposable monthly income across the countries and periods covered by the analysis sample are displayed in Figure 1. The figure, based on adaptivekernel densities (Van Kerm, 2003), shows to what extent income distributions across France, Germany, Italy, Spain, and Sweden evolved during different phases of the COVID-19 pandemic. Red vertical lines display national poverty lines, expressed in 2019 US dollars. Despite equivalised income taking only a discrete number of values, given by combinations of the six income bands and the squared root of household size, I here consider it as being a continuous variable for ease of representation. Bunching around common combinations of income bands and family size is therefore to be expected, and appears to be relatively more common around the poverty thresholds in Italy and Spain. Despite data limitations do not allow us to observe precise income data, the close matching between COME-HERE inequality measures as reported in Clark et al. (2020) and Eurostat official statistics on inequality in Europe, as well as Table 2 in this paper, are suggestive evidence that the income distributions observed in COME-HERE are accurate ones. The pattern emerging from Figure 1 confirms the descriptive statistics presented in Table 1: with respect to January 2020, income distributions in May appeared to move increasingly to the left, more so for Italy, Spain, and Sweden. Furthermore, all countries experience a shift in population densities in the same time window, with more people reporting equivalised income values below the poverty line. However, by September 2020, income distributions converged back to their January levels - albeit not perfectly, and mostly in Germany and France. As family size is only observed in wave 1, these changes are only driven by variations in reported income and do not reflect demographic changes.

The main results of the paper are displayed in Table 3 . The table reports a set of poverty measures across January, May, and September 2020, namely the mean poverty gap among the poor and $F G T(\alpha)$ for $\alpha=\{0,1,2\}$. Exploiting the additive subgroup decomposability property 
of the indices, it does so first for the whole analysis sample, and then by country subgroup. Comparing poverty measures for all countries over time, it appears that poverty has progressively worsened from January to May, with the headcount ratio increasing by $4 \mathrm{pp}$. Not only this is true in terms of incidence $(F G T(0))$, as already suggested by descriptive statistics in Table 1, but also according to the intensity and inequality dimensions of poverty. The average normalised poverty gap FGT(1) increased, meaning that poor individuals are on average further away from the poverty line; the higher squared poverty gap $F G T(2)$ suggests a more unequal income distribution below the poverty line. Figures from September 2020 show a recovery from May's levels, although a partial one.

Different situations could however be observed in the five countries in the sample. While all countries appear to have suffered a higher poverty intensity, incidence, and inequality from January to May, some recovered faster than others. In France and Spain, under the same $F G T(0), F G T(1)$ and $F G T(2)$ appear to have reached even lower levels in September, as compared to January; Germany, Italy, and Sweden, on the contrary, still displayed higher poverty levels in September than they did at the beginning of the year (with increases in headcount ratios of 2, 3 and $2 \mathrm{pp}$, respectively).

It could be tempting to compare poverty features across countries based on Table 3 . However, the absence of a unique cross-country poverty line makes it impossible to make any accurate dominance consideration. Figure 2 is an attempt to overcome this limitation, by adopting one unique poverty line based on $60 \%$ of the median PPP-adjusted equivalised income of the whole analysis sample in January 2020. The figure plots relative TIP curves in January, May, and September 2020 for all five countries, based on this new universal poverty line of 1341.28 (in 2019 USD). Headcount ratios, measured as the cumulative population share at which each TIP curve becomes flat, are projected on the $\mathrm{x}$ axes. The intensity of poverty can be seen as the maximum height reached by the curves, and its inequality is given by the slope 
at which the curves move from the origin to the point where they become flat. The closer one country's TIP curve is to the poverty worst-case scenario (i.e. a line departing from the origin with slope one), the worse that country is faring in terms of poverty according to its three dimensions. Exact figures on the headcount ratios, poverty gap ratios, and squared poverty gaps from Figure 2 are reported in Table A2 and closely mirror the ones reported in the first panel of Table 3 -with the exception of Italy and Spain, where the higher poverty threshold yields larger values for $F G T(0), F G T(1)$, and $F G T(2)$ in January. The poverty ranking suggested by the TIP curves in Figure 2 in January 2020 sees Germany as the least poor of all countries, according to all three dimensions, closely followed by France. Sweden's TIP distribution, while displaying a lower headcount, stochastically dominates France's and Germany's and, as such, fares as the poorest of the three. Italy and Spain are the poorest countries according to all three dimensions, their TIP curves being almost indistinguishable in terms of inequality, but with larger poverty incidence and intensity in Italy. Moving to May 2020, the worsening of poverty makes dominance patterns clearer, without altering the countries' rankings. However, recovery patterns in September 2020 affected Germany and France's relative poverty dominance ranking, with France becoming the least poor of all five countries. As compared to January, the final TIP curves in September 2020 see the central and northern European economies becoming more similar to each other in all poverty dimensions, while drifting further away from Spain's almost constant position. Italy's TIP curve, on the contrary, is the furthest from its initial position in January, still suffering the economic consequences of the first waves of COVID19.

The countries in the analysis sample not only differ greatly from each other, but they also encompass very different realities within their own geographical borders. Historical, cultural, and socio-economic backgrounds all contribute to heterogeneity across territorial areas within the same country in experiencing different degrees of poverty and deprivation. Additionally, 
the role of local governments in the management of pandemic responses might interact with initial geographical predispositions to poverty. The COME-HERE data, providing representative geographical disaggregation at the NUTS 1 level, constitute the perfect tool to further zoom in into geographical decompositions of the poverty consequences of COVID-19. Figure 3 shows the evolution of the headcount ratio over time across the NUTS 1 territorial areas represented in the survey. The figure shows a general increase in poverty rates across most territorial areas in Italy, Spain, and Sweden between January and May. The evolution of poverty across Germany and France appears more nuanced, with the central and western-most regions of Germany and the French south and south-east being the most visibly affected. Consistently with results from Table 3, poverty rates in September are closer to the January ones, although recovery patterns appear to differ from area to area.

While Figure 3 provides a visual representation of the regional evolution of poverty in the countries in the sample, its narrative is sensitive to the choice of poverty thresholds in the legend (here chosen as multiples of 0.05 that were the closest to quintiles of the distribution of poverty across regions). Table A3 provides the level of detail missing in Figure 3 , that is the precise headcount ratios by NUTS 1 and time. While confirming the evidence inferred from Figure 3, Table A3 further identifies a more ubiquitous increase in poverty rates between January and May, with Brandenburg, Niedersachsen, and Sachsen in Germany, and Île-deFrance, Nord - Pas-de-Calais, and Centre-Est in France being the only areas where a small decrease was observed instead. Additionally, the table shows that in Italy and Spain preexisting geographical inequalities in poverty rates were exacerbated as COVID-19 progressed, so that poorest areas such as the North West of Spain (Noroeste) or the Italian Islands (Isole) were hit the most - with poverty rates reaching almost $40 \%$ in May. 


\subsection{Heterogeneity Analysis: The Role of Individual Characteristics}

Other than geography, additional characteristics are likely to play a role in shaping the dynamics of poverty as COVID-19 progresses. Individual factors determined prior to the lockdown, such as age, gender, and employment status in January 2020, can have a protective effect or rather exacerbate the individual risk of falling into poverty. Figures 4 to 8 investigate the evolution of poverty between January and September 2020 in each country by plotting TIP curves across population subgroups. Precise figures on poverty across these subgroups are provided in Appendix Tables A6 to A10, reporting population shares, the mean poverty gap for the poor, as well as $F G T(0), F G T(1)$, and $F G T(2)$. Figure 4 first looks at differences by gender. Consistently with official statistics, ${ }^{9}$ in January 2020 women all over the sample were more likely than man to be at risk of poverty, according to all three dimensions represented by the TIP curves. While the TIP curves changed during the pandemic for both groups, the changes were never large enough to affect the ranking between the two genders, with women being at all times poorer than men. Focussing on differences from January to May, Figure 4 additionally shows an increase in poverty in all countries for both men and women (with the exception of women in Sweden), although with different magnitudes. The increase was disproportionately larger according to all three dimensions of poverty for Spanish and Italian women, the poverty gender gap in May 2020 widening as a result in the two countries. On the contrary, only men become poorer in Sweden, narrowing the poverty gender gap. TIP curves are on average lower in September 2020, with both men and women reaching January's TIP curve's level or lower in France, Spain, and Sweden. The recovery from May to September appears to be slower in Italy, especially for men; in Germany, where the TIP curves in all periods are the closest to each other, poverty levels in September appear to be quite close to May's ones.

\footnotetext{
${ }^{9}$ See Eurostat Europe 2020 indicators: https://ec.europa.eu/eurostat/data/database.
} 
Turning to age heterogeneity, Figure 5 shows different pictures across countries in the sample. In January 2020, individuals above the median age of 51 had higher initial levels of poverty in Germany, Italy, and Sweden, and lower levels in France and Spain. Regardless of the departing point, TIP curves of young individuals experienced the highest degree of variability across the sample period - suggesting that they are the group who has suffered the most from the COVID-19 crisis. Despite the higher poverty levels reached in May, September's $T I P$ curves were back to January levels or lower for all countries - except in Italy and Germany, where the recovery was slower.

Figures 6 and 7 show, respectively, whether education (having at least a secondary education degree) and employment (having a job in January 2020) had any protective effects against the risk of poverty in COVID-19 times. From Figure 6, it is clear that the TIP curves of respondents with only a primary education degree always poverty-dominate the curves of more educated individuals. Furthermore, education has a small dampening effect on the higher poverty rates experienced by German and Spanish respondents in May, as compared to January. However, it did not appear to play a protective role against the higher risk of poverty following the beginning of the COVID crisis in the other three countries. Overall, from January to September, the COVID-19 crisis appears to have reduced initial differences in the risk of poverty across educational subgroups for France and Spain, while it contributed to exacerbating those initial differences in the other countries. Similarly to education, Figure 7 shows that individuals who had a job in January 2020 are always less poor than those who did not have a job in all countries in the sample. However, here employment does not play a protective role against the risk of experiencing more severe poverty in May 2020: across all countries, notemployed individuals experienced a relatively small increase in poverty as compared to their fellow employed countrymen. TIP curves for September 2020 reflect this tendency as well: as compared to initial January levels, the recovery from the disproportionately higher increase in 
poverty rates experienced by employed individuals in May was limited, so that between January and September the poverty gap between employed and not-employed individuals was overall reduced.

\section{Sensitivity Analysis}

I here perform a battery of sensitivity tests, in order to assess how robust results presented in Section 3 are to the poverty line specification, the measurement of equivalised income, and sample selection. So far, I computed relative poverty lines based on income distributions in the COME-HERE survey. However, the survey is nationally representative only in terms of gender, region, and age. So it could be the case that income distributions are, for instance, skewed towards the left due to the underreporting of top income values - as it oftentimes is the case in survey data. Furthermore, the incomes reported in the survey are banded, and as such might miss a detailed enough level of variability to make precise inference. Consequently, the COME-HERE national poverty lines displayed in column 4 of Table 2 take only three distinct values. For this reason, I now turn to Eurostat relative poverty lines, in order to try and have a more accurate measure of at-risk-of-poverty thresholds. Furthermore, Eurostat relative poverty lines are available for two different kinds of households, in order to account for economies of scale across individuals sharing economic resources: a one-person household (displayed in column 1 of Table A4), and a two-adults two-children below 14 years old household (column 4 of Table A4). Using a linear interpolation between the Eurostat poverty lines, I additionally derive the poverty lines in columns 2 and 3, to be used for a two-persons and a three-persons household, respectively.

Results using the high-detailed poverty lines from Table A4 are displayed in Table A5. Comparing the January 2020 FGT(0) figures from Table A5 with official at-risk-of-poverty rates from Table 2, it appears that the poverty lines used in Table A5 verge towards an 
overestimation of the number of people at risk of poverty in the COME-HERE survey. On average, with respect to results from Table 3, poverty in Table A5 appears to be more severe in all countries - not only in terms of headcount ratio, but also for the other dimension of poverty. The same considerations hold also for May and September. The only exception is Spain, for which the headcount ratio stayed the same in May and September, while the poverty gap ratio and the squared poverty gap are slightly reduced. Furthermore, the distance between Spain and Italy - the two countries where poverty reached the highest levels during COVID19 - appears to be larger in Table A5, with the fraction of individuals at risk of poverty in Italy reaching up to $38 \%$ in May $2020 .{ }^{10}$ Qualitatively, the countries' poverty ranking according to the three ' $i$ 's of poverty in May 2020 is the same across Table 3 and Table A5.

Another potential concern is related to the measurement of equivalent income. Results presented in section 3 rely on the definition of household size, which is modified with respect to what is directly reported by respondents as to include considerations on shared housing among individuals constituting different household nuclei. However, these considerations imply normative assumptions on unobserved household types, which may well not be met: for instance, young working adults below the age of 40 with no children who report living with other adult household members, may be taking care of their parents or other relatives instead of sharing their housing with economically-independent house-mates. As such, the household size they report would indeed be the correct one and restricting it might induce an underestimation of poverty. Table A11 replicates Table 3 using a definition of equivalised household disposable income that does not apply any restrictions to family size as reported by respondents. As expected, what emerges from the table are slightly higher poverty figures

\footnotetext{
${ }^{10}$ Italy's higher poverty rates are mostly driven by data bunching: depending on the wave considered, between 6.6 and $7.4 \%$ of Italian respondents have equivalised income of 812.5 , which corresponds to individuals living in a four-persons household and reporting an income level between 1250 and 2000 euros per month. The COMEHERE poverty threshold (column 4 of Table 2) is right below that level of equivalised income (805 euros); Eurostat's one is right above (858.3 euros).
} 
throughout the observational window, as compared to those in Table 3, with headcount ratios being on average one percentage point larger.

Lastly, I consider whether some of the considerations made so far are sensitive to the inclusion of retired respondents in the analysis sample. Retired respondents might in fact be more protected from the adverse economic consequences of COVID-19 with respect to other individuals, due to their relatively stable pension income flow. In particular, individuals in retirement age are likely to be over-represented in some groups of the heterogeneity analysis presented in section 3.2, such as individuals above the median age and individuals who did not have a job in January 2020. Appendix Figures A1 and A2 address whether results presented in Figures 5 and 7 (and their equivalents in Tables A6 to A10) are robust to the exclusion of individuals aged 65 years old and above. As compared to Figure 5, results in Figure A1 (now using 44 as the median age) are qualitatively the same for Germany. However, results for France, Italy, Spain, and Sweden suggest that the poverty rates of older working-age individuals were underestimated for all periods in Figure 5: the gap between old and young individuals is now smaller in Figure A1, with older respondents' poverty experience in May being closer to the one of younger respondents.

Moving towards poverty differences across employment status in January 2020, Figure A2 shows that when excluding individuals above age 65 from the sample the TIP curves of nonemployed respondents are on average higher in all periods. However, the relative distance between the TIP curves of employed and non-employed respondents appears to shrink over time in almost all countries, confirming that - even after excluding individuals of retirement age - COVID-19 hit disproportionately more those who had a job in January 2020. 


\section{Conclusions}

The paper uses real-time longitudinal survey data to describe the evolution of poverty across five European countries - from prior to the diffusion of COVID-19 in Europe, up to September 2020. I find that between January and May poverty rates have increased on average by $4 \mathrm{pp}$, with significant country-level differences (ranging from $9 \mathrm{pp}$ in Italy to $1 \mathrm{pp}$ in France). By September, poverty rates decreased again - although remaining 1 pp higher than January levels. Consistently with poverty rates, other measures of poverty such as the poverty gap ratio and the squared poverty gap are concordant in identifying an increase, and then a decrease, in all dimensions of poverty. Within-country geographical heterogeneity appears to suggest that the increase in poverty was almost ubiquitous, with few exceptions in France and Germany, and that it contributed to aggravate pre-existing inequalities across regions in Italy and Spain.

Other than geography, individual characteristics play a role in determining individual exposure to poverty: young respondents, women, and those who were employed prior to the spread of the pandemic have born the highest increases in poverty during the first wave of COVID-19, on average.

Some caveats hold when interpreting the results of this paper. Firstly, non-random attrition of individuals with higher risk of poverty is likely to constitute a source of attenuation bias for the figures presented in the paper. Additionally, results are restricted to a small set of WestEuropean countries and relatively small sample sizes make it harder to obtain representative estimates of poverty for each subgroup considered in the analysis. Finally, the paper does not allow to establish a causal link between the evolution of the poverty figures and the COVID19 crisis per se: in absence of counterfactual scenarios, I am not able to assess to what extent results might have been driven by the health emergency, lockdown-style measures, governments recovery and help schemes, or unobserved confounding factors. Despite the limitations, the paper provides a compelling first picture of poverty during the pandemic. 
Results suggest that, while suffering higher poverty levels during the first months of the COVID-19 crisis, governments in France, Germany, Italy, Spain, and Sweden were successful in containing the adverse poverty effects of the pandemics later in the year. Additional evidence would be needed in order to disentangle the role of individual policies and explain crosscountries differences. 


\section{References}

Adams-Prassl, A., Boneva, T., Golin, M., and Rauh, C. (2020). Inequality in the impact of the coronavirus shock: Evidence from real time surveys. Journal of Public Economics, 189.

Ali, S., Asaria, M., and Stranges, S. (2020). COVID-19 and inequality: are we all in this together? Canadian Journal of Public Health, 111, 415-416.

Almeida, V., Barrios, S., Christl, M., De Poli, S., Tumino, A., and van der Wielen, W. (2020). Households' income and the cushioning effect of fiscal policy measures during the Great Lockdown. Joint Research Centre Working Papers on Taxation and Structural Reforms No. 06/2020.

Alon, T., Doepke, M., Olmstead-Rumsey, J., and Tertilt, M. (2020). The impact of COVID-19 on gender equality. NBER Working Paper No. 26947.

Beland, L. P., Brodeur, A., and Wright, T. (2020). The short-term economic consequences of COVID-19: Exposure to disease, remote work and government response. IZA Discussion Paper No. 13159.

Berger, D. W., Herkenho, K. F., and Mongey, S. (2020). An SEIR infectious disease model with testing and conditional quarantine. NBER Working Paper No. 26901.

Blundell, R., Costa Dias, M., Joyce, R., and Xu, X. (2020). COVID-19 and Inequalities. Fiscal Studies, 41, 291-319.

Brewer, M., and Gardiner, L. (2020). Return to spender: Findings on family incomes and spending from the Resolution Foundation's coronavirus survey. Resolution Foundation.

Bronka, P., Collado, D., and Richiardi, M. (2020). The Covid-19 crisis response helps the poor: The distributional and budgetary consequences of the UK lock-down. EUROMOD Working Papers Series No. EM 11/20.

Chakravarty, S. R. (1983). Ethically flexible measures of poverty. Canadian Journal of Economics, 16, 74-85.

Clark, A. E., and Senik, C. (2010). Who compares to whom? The anatomy of income comparisons in Europe. Economic Journal, 120, 573-594. 
Clark, A. E., D'Ambrosio, C., and Lepinteur, A. (2020). The Fall in Income Inequality during COVID-19 in Five European Countries. ECINEQ Working Paper Series No. 2020-565.

Delaporte, I., Escobar, J., and Peña, W. (2020). The distributional consequences of social distancing on poverty and labour income inequality in Latin America and the Caribbean. Global Labor Organization Discussion Paper No. 682.

Eurostat (2007). Regions in the European Union - Nomenclature of territorial units for statistics, NUTS 2006 /EU-27. Eurostat methodologies and working papers, ISSN 19770375 .

Fetzer, T., Hensel, L., Hermle, J., and Roth, C. (2020). Coronavirus perceptions and economic anxiety. arXiv:2003.03848.

Figari, F., and Fiorio, C. V. (2020). Welfare resilience in the immediate aftermath of the covid19 outbreak in Italy. EUROMOD Working Papers Series No. EM 06/20.

Foster, J., Greer, J., and Thorbecke, E. (1984). A class of decomposable poverty measures. Econometrica, 52, 761-766.

Hale, T., Angrist, N., Cameron-Blake, E., Hallas, L., Kira, B., Majumdar, S., Petherick, A., Phillips, T., Tatlow, H., Boby, T., and Webster, S. (2020). Variation in government responses to COVID-19. Version 9.0. Blavatnik school of government working paper, 32.

Han, J., Meyer, B. D., and Sullivan, J. X. (2020). Income and Poverty in the COVID-19 Pandemic. NBER Working Paper No. 27729.

Haug, N., Geyrhofer, L., Londei, A. et al. (2020). Ranking the effectiveness of worldwide COVID-19 government interventions. Nature Human Behaviour, https://doi.org/10.1038/s41562-020-01009-0.

Jenkins, S. P., and Lambert, P. J. (1997). Three 'I's of poverty curves, with an analysis of UK poverty trends. Oxford Economic Papers, 49, 317-327.

Jones, C. J., Philippon, T., and Venkateswaran, V. (2020). Optimal mitigation policies in a pandemic: Social distancing and working from home. NBER Working Paper No. 26984. 
Jordà, Ò., Singh, S. R., and Taylor, A. M. (2020). Longer-run economic consequences of pandemics. NBER Working Paper No. 26934.

Li, J., Vidyattama, Y., La, H. A., Miranti, R., and Sologon, D. M. (2020). The Impact of COVID-19 and Policy Responses on Australian Income Distribution and Poverty. arXiv preprint arXiv:2009.04037.

Palomino, J.C., Rodríguez, J.G., and Sebastian, R. (2020). Wage inequality and poverty effects of lockdown and social distancing in Europe. Covid Economics, 25, 186-229.

Platt, L., and Warwick, R. (2020). Are some ethnic groups more vulnerable to COVID-19 than others? Institute for Fiscal Studies and Nuffield Foundation. London, UK.

Shorrocks, A. F. (1995). Revisiting the Sen poverty index. Econometrica, 63, 1225-1230.

Stephany, F., Stoehr, N., Darius, P., Neuhauser, L., Teutlo, O., and Braesemann, F. (2020). The CoRisk-Index: A data-mining approach to identify industry-specific risk assessments related to COVID-19 in real-time. Covid Economics, 41, 129-146.

Van Kerm, P. (2003). Adaptive kernel density estimation. Stata Journal, 3, 148-156.

Watts, H. (1968). An economic definition of poverty. In Moynihan, D. P. (ed.), On Understanding Poverty: Perspectives from the Social Sciences, Basic Books, New York, NY. 


\section{Figures and Tables}

Figure 1: Equivalised income distributions across time and country
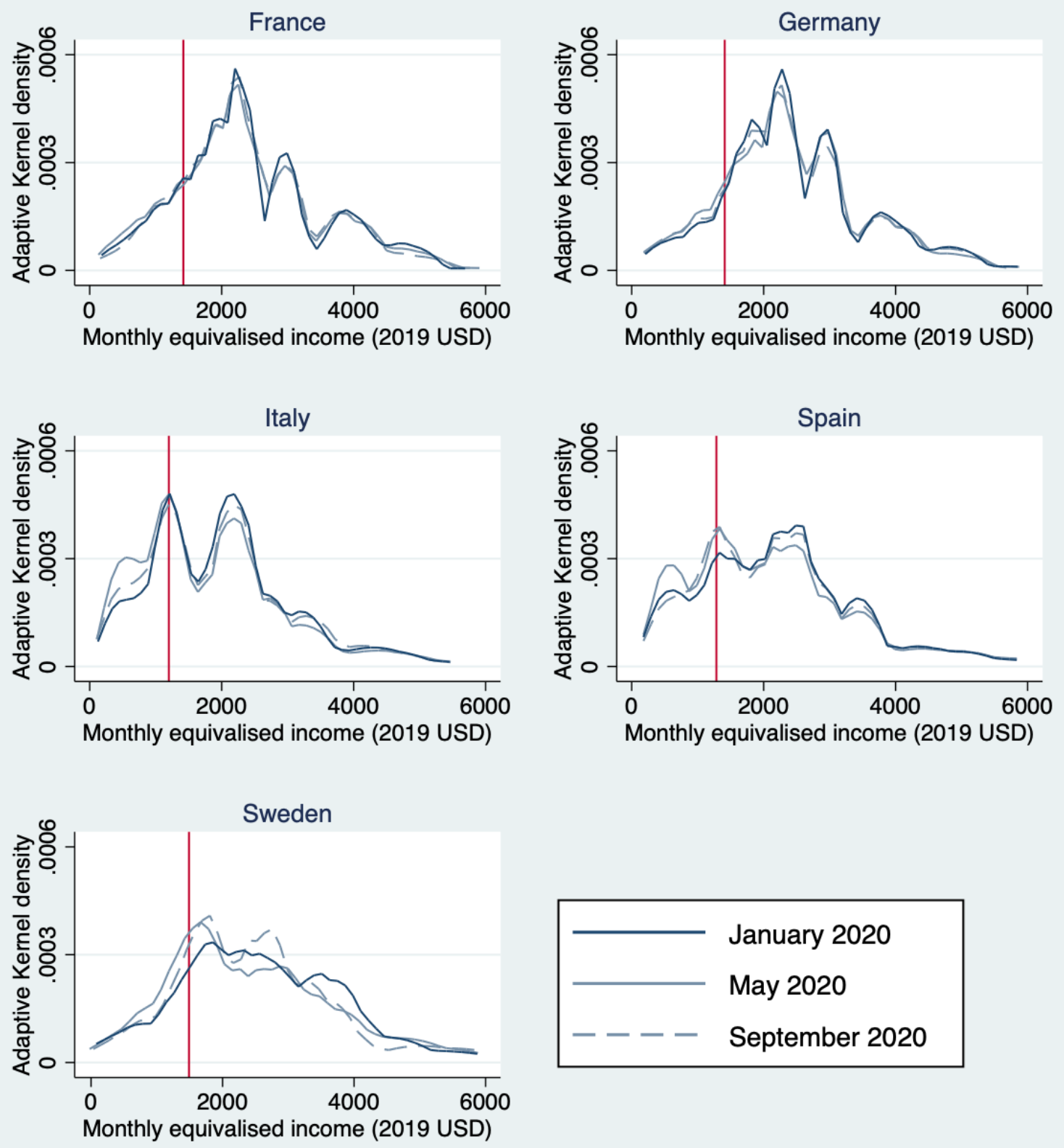

Notes. The figure is based on equivalised household income distributions by country. Country-specific poverty lines, computed as $60 \%$ of the median of the national equivalised income distributions in January 2020, are reported vertically in each graph. Distributions are truncated at 6000 USD per month (between the 95th and the $99^{\text {th }}$ percentile of income) for ease of graphical representation. 
Figure 2: Relative TIP curves by country and interview date (unique poverty line)

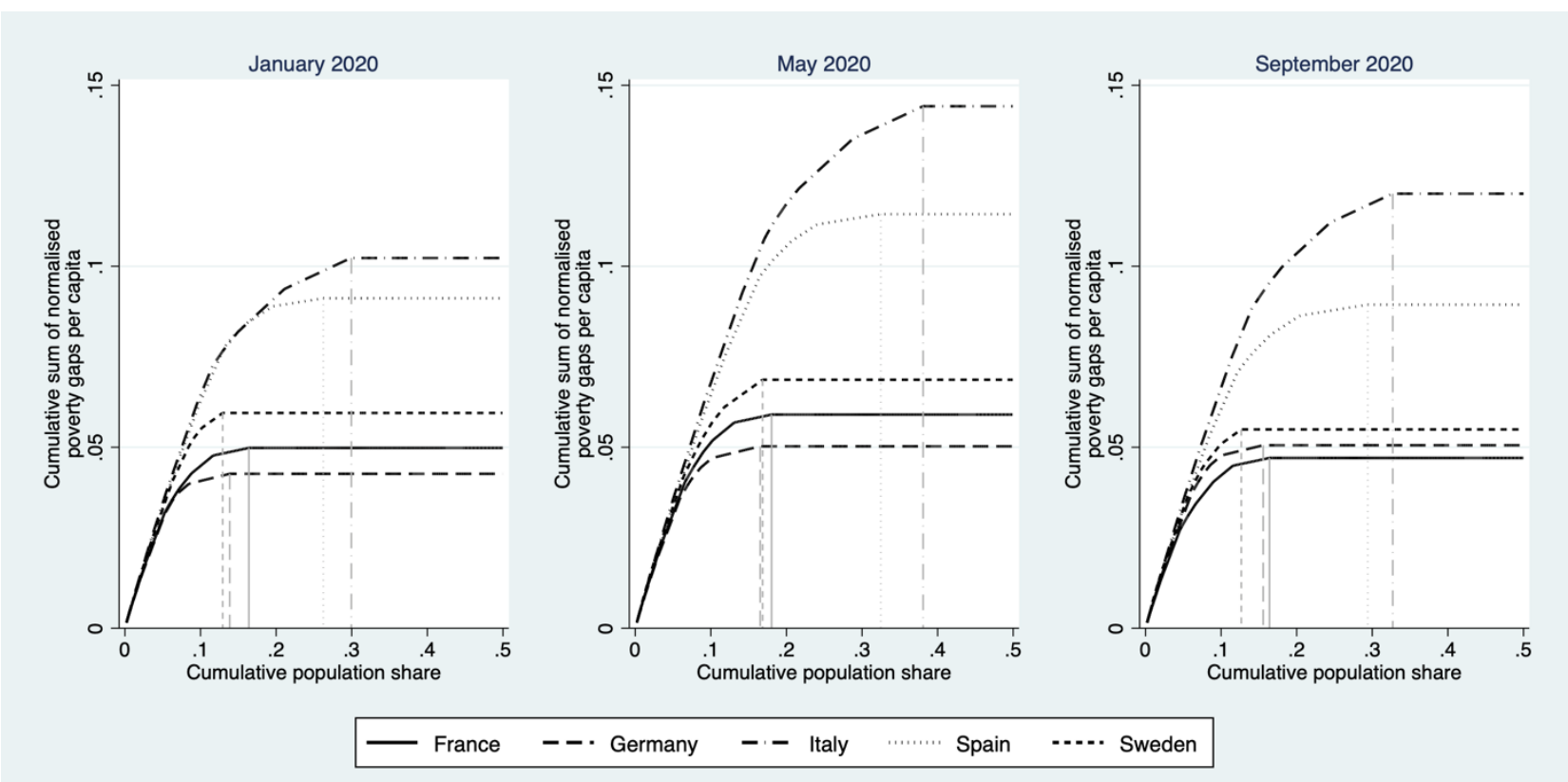

Notes. The figure is based on equivalised household income distributions by country, and a unique poverty line, computed as $60 \%$ of the median of the whole equivalised income distribution in January 2020 (weighted by household size and country population shares). 
Figure 3: The evolution of the headcount ratio across regions
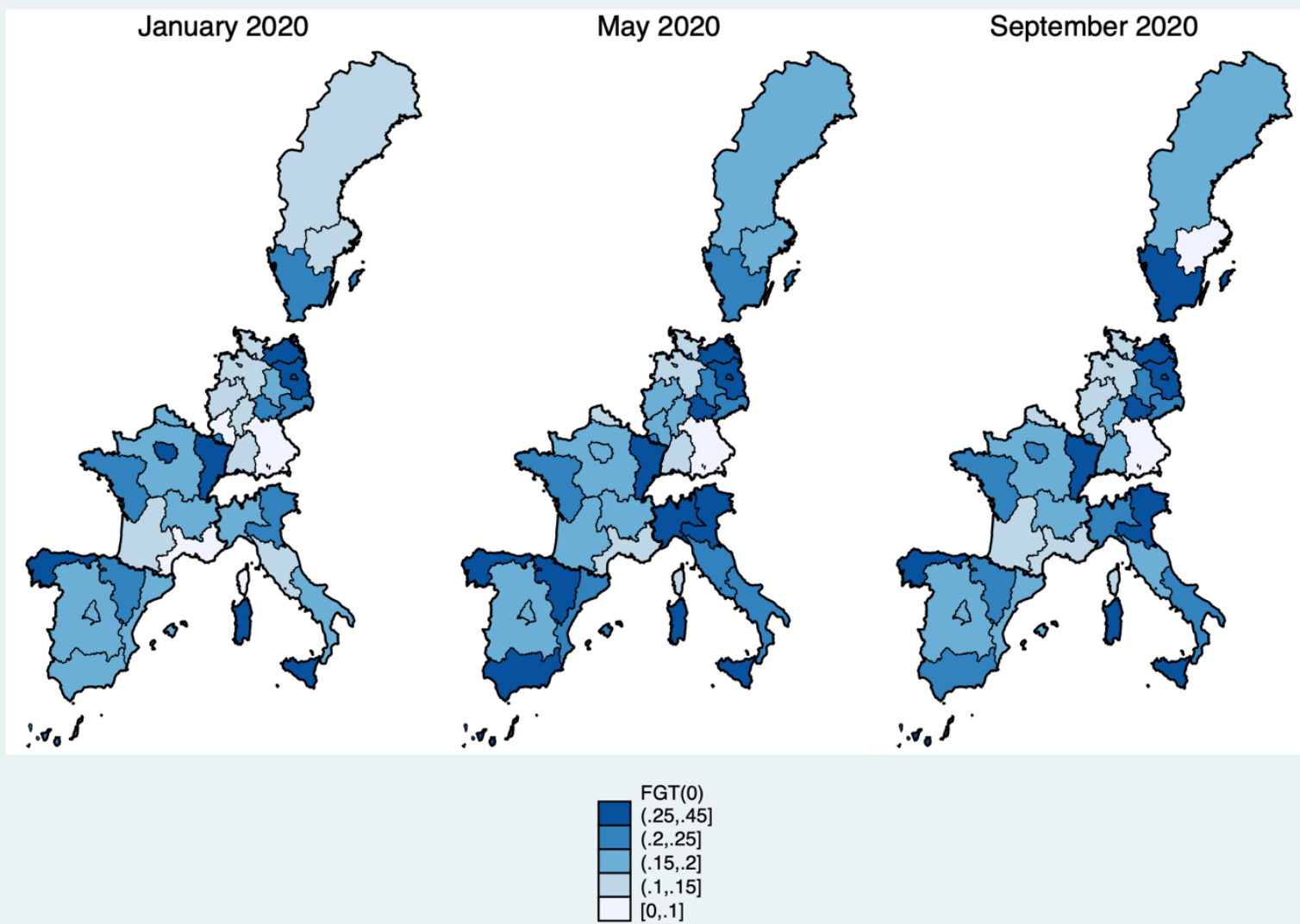

Notes. Regions refer to NUTS 1 territorial units, according to the 2006 classification (see Eurostat, 2007). Geocoordinates for the Canary Islands (bottom left of the figures) are translated upwards and rightwards to better fit the graphical representation. 
Figure 4: Relative TIP curves by country, interview date, and gender
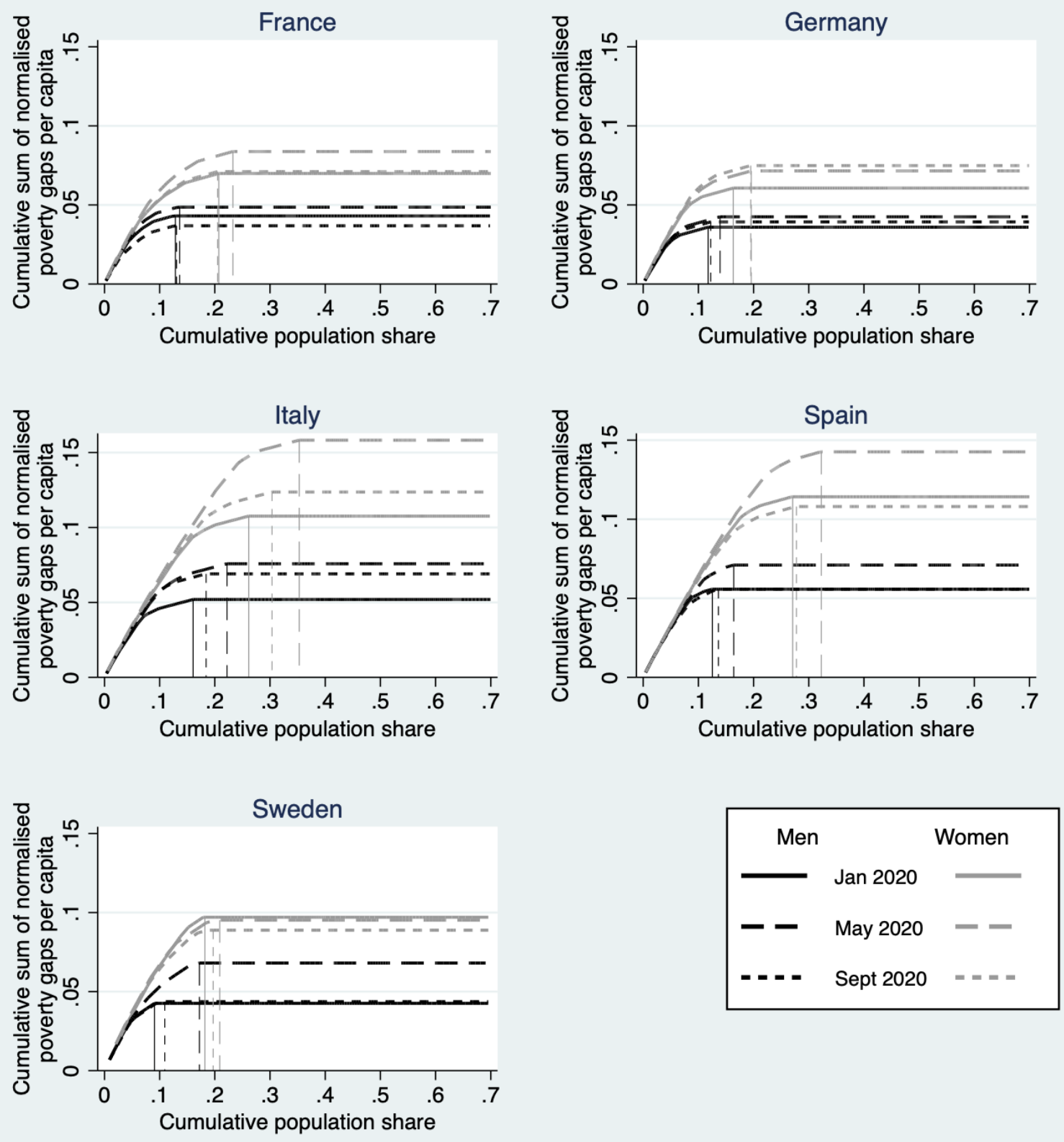

Notes. The figure is based on equivalised household income distributions by country, and country-specific poverty lines, computed as $60 \%$ of the median equivalised income distribution in January 2020 . The points where $T I P$ curves become flat are projected on the $\mathrm{x}$ axis, to indicate the value of $F G T(0)$. The exact values of the $F G T(0)$, $F G T(1)$, and $F G T(2)$ indices are reported for each country, respectively, in Tables A6 to A10. 
Figure 5: Relative TIP curves by country, interview date, and age
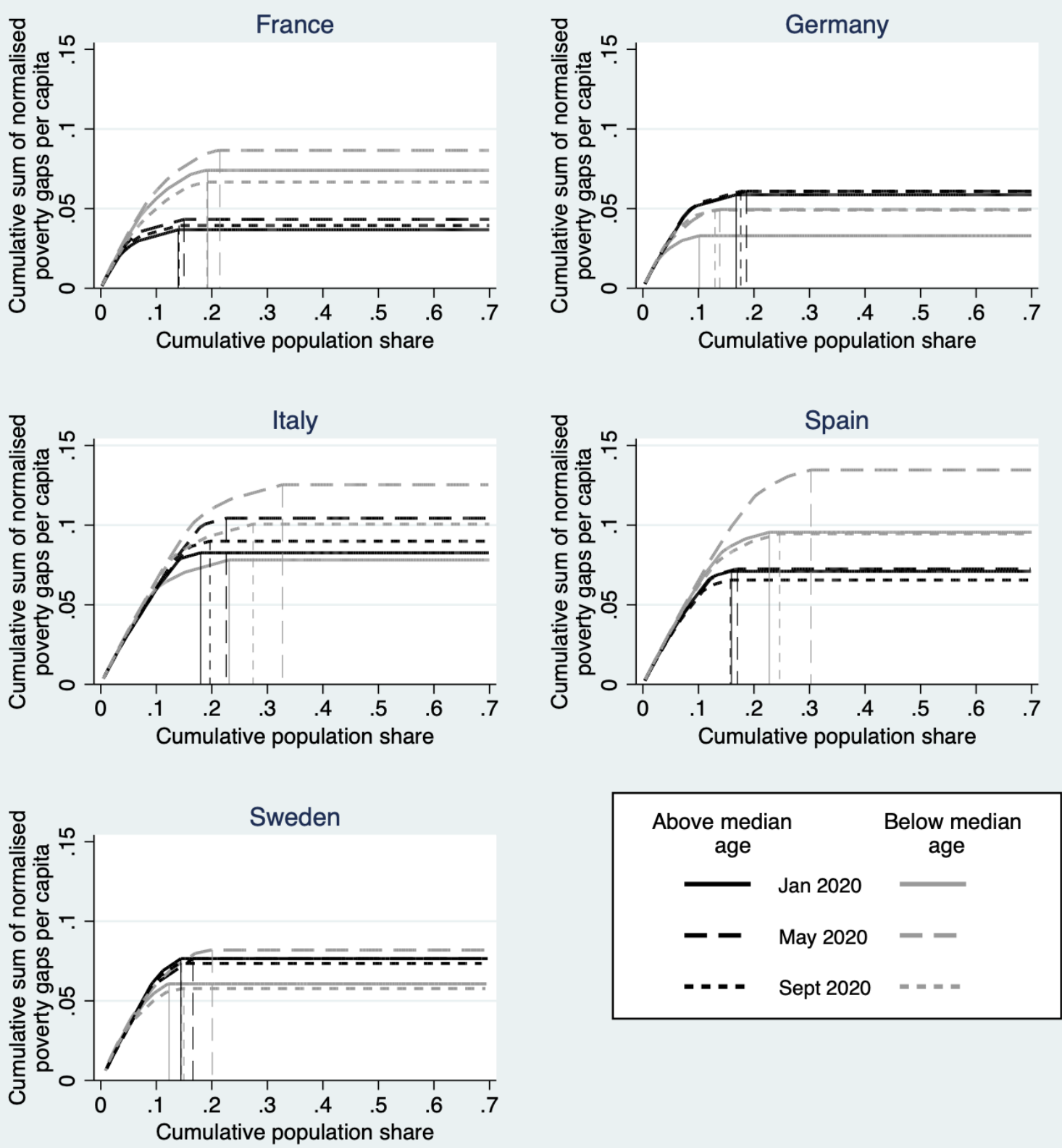

Notes. The figure is based on equivalised household income distributions by country, and country-specific poverty lines, computed as $60 \%$ of the median equivalised income distribution in January 2020 . The points where TIP curves become flat are projected on the $\mathrm{x}$ axis, to indicate the value of $F G T(0)$. The exact values of the $F G T(0)$, $F G T(1)$, and FGT (2) indices are reported for each country, respectively, in Tables A6 to A10. 
Figure 6: Relative TIP curves by country, interview date, and education
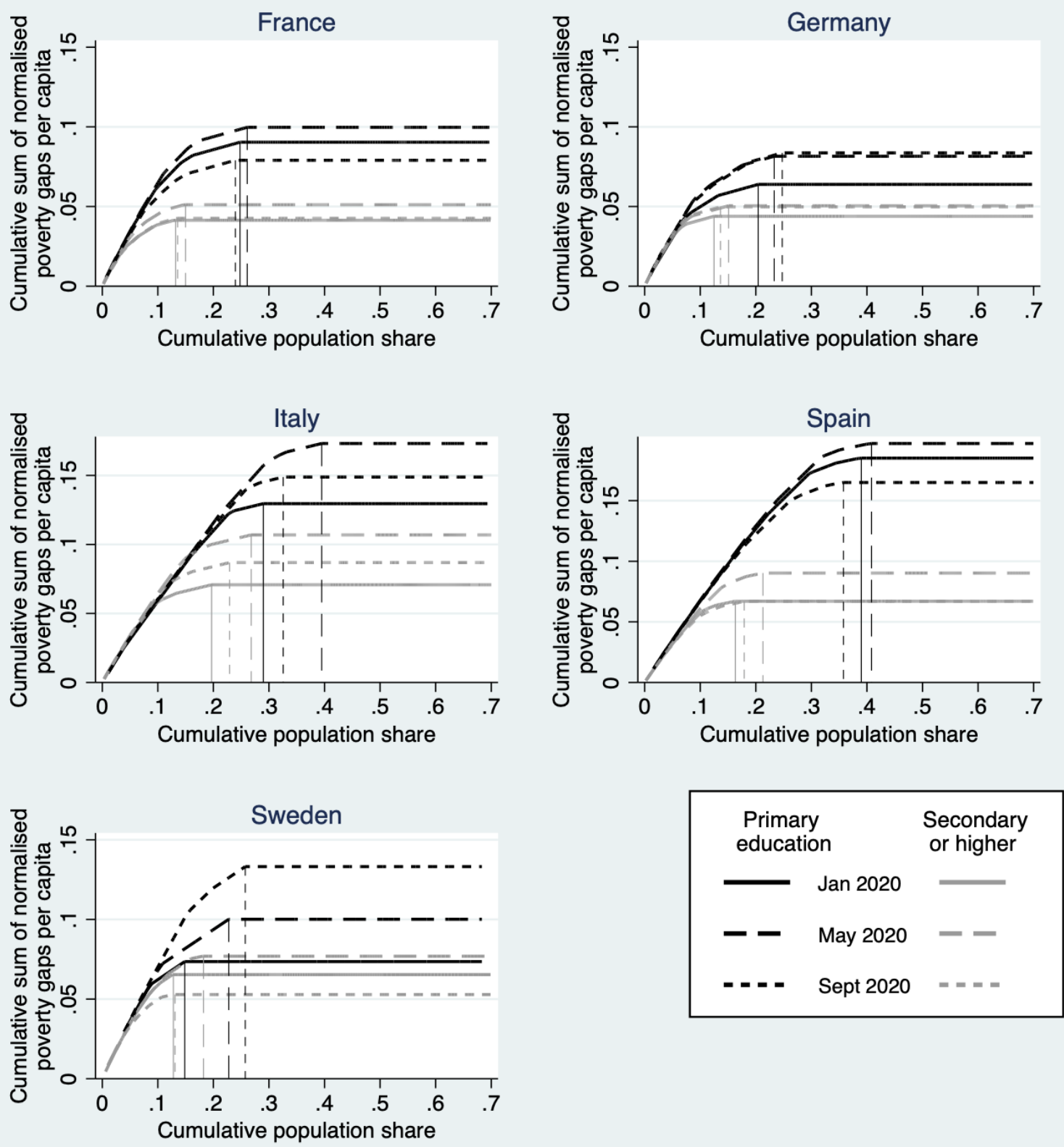

Notes. The figure is based on equivalised household income distributions by country, and country-specific poverty lines, computed as $60 \%$ of the median equivalised income distribution in January 2020 . The points where TIP curves become flat are projected on the x axis, to indicate the value of $F G T(0)$. The exact values of the $F G T(0)$, FGT(1), and FGT(2) indices are reported for each country, respectively, in Tables A6 to A10. 
Figure 7: Relative TIP curves by country, interview date, and employment status in January 2020
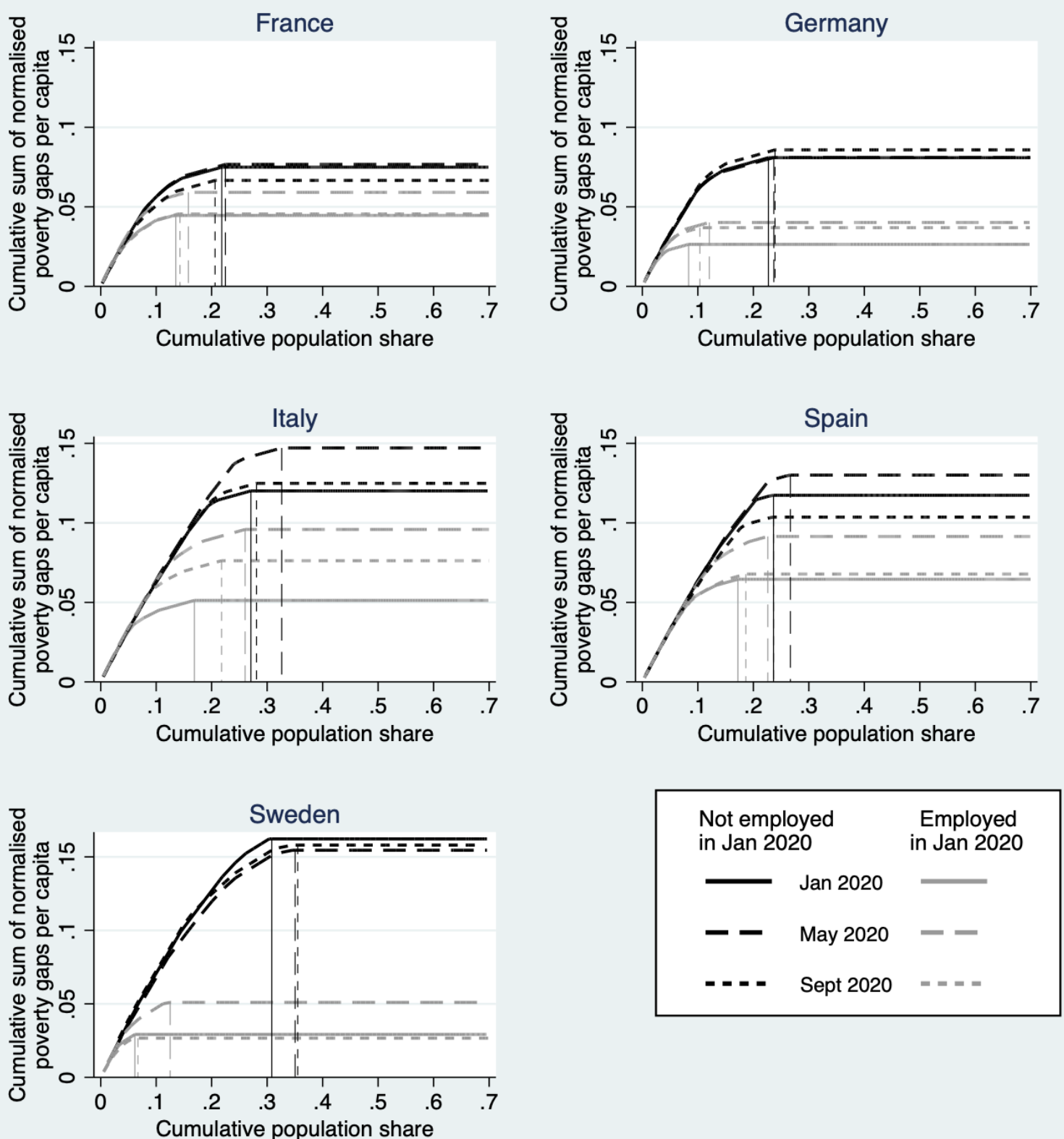

Notes. The figure is based on equivalised household income distributions by country, and country-specific poverty lines, computed as $60 \%$ of the median equivalised income distribution in January 2020 . The points where TIP curves become flat are projected on the x axis, to indicate the value of $F G T(0)$. The exact values of the $F G T(0)$, $F G T(1)$, and FGT (2) indices are reported for each country, respectively, in Tables A6 to A10. 
Table 1: Descriptive statistics for the analysis sample

\begin{tabular}{lcccc}
\hline & Mean & Std. Dev. & Min & Max \\
\hline Equivalised income (PPP) & & & & \\
January 2020 & $2,570.22$ & $1,775.77$ & 310.48 & $22,354.70$ \\
May 2020 & $2,433.25$ & $1,698.83$ & 287.34 & $23,923.45$ \\
September 2020 & $2,439.31$ & $1,662.732$ & 287.34 & $16,347.45$ \\
At-risk-of-poverty & & & & \\
January 2020 & 0.18 &. & 0 & 1 \\
May 2020 & 0.22 &. & 0 & 1 \\
September 2020 & 0.19 &. & 0 & 1 \\
Time-invariant characteristics & & & & \\
Poverty line (PPP) & $1,332.11$ & 98.13 & $1,199.7$ & $1,489.7$ \\
Household size & 3.63 & 1.50 & 1 & 9 \\
Age & 49.49 & 14.58 & 18 & 93 \\
Female & 0.48 &. & 0 & 1 \\
Primary education & 0.19 &. & 0 & 1 \\
Secondary education & 0.37 &. & 0 & 1 \\
Tertiary education & 0.44 &. & 0 & 1 \\
Employed in January 2020 & 0.62 &. & 0 & 1 \\
Resident in France & 0.23 &. & 0 & 1 \\
Resident in Germany & 0.20 &. & 0 & 1 \\
Resident in Italy & 0.26 &. & 0 & 1 \\
Resident in Spain & 0.25 &. & 0 & 1 \\
Resident in Sweden & 0.06 &. & 0 & 1 \\
\hline Nesin & & & \\
\end{tabular}

Notes. Descriptive statistics based on the analysis sample (balanced panel of 4,078 individuals across three time periods).

Table 2: At-risk-of-poverty rates across countries

\begin{tabular}{|c|c|c|c|c|}
\hline & \multicolumn{2}{|c|}{$\begin{array}{c}\text { Eurostat } \\
\text { (2019) }\end{array}$} & \multicolumn{2}{|c|}{$\begin{array}{c}\text { COME-HERE } \\
\text { (Jan. 2020) }\end{array}$} \\
\hline & $\begin{array}{l}A R P \\
\text { (1) }\end{array}$ & $\begin{array}{c}z \\
(2)\end{array}$ & $\begin{array}{l}A R P \\
(3)\end{array}$ & $\begin{array}{c}z \\
(4)\end{array}$ \\
\hline France & 0.136 & 1128.1 & 0.167 & 1039.2 \\
\hline Germany & 0.148 & 1175.8 & 0.139 & 1039.2 \\
\hline Italy & 0.201 & 858.3 & 0.211 & 805.0 \\
\hline Spain & 0.207 & 750.8 & 0.196 & 805.0 \\
\hline Sweden & 0.171 & 1223.7 & 0.131 & 1224.7 \\
\hline \multicolumn{5}{|c|}{$\begin{array}{l}\text { Notes. Column } 1 \text { reports official at-risk-of-poverty }(A R P) \text { rates, } \\
\text { where the poverty line } z \text { reported in column } 2 \text { is computed as } 60 \% \\
\text { of the median equivalised income in each country for a one- } \\
\text { person household, derived from EU-SILC (Source: Eurostat, } \\
\text { 2019). Columns } 3 \text { and } 4 \text { are based on the COME-HERE survey, } \\
\text { using the same poverty line definition (here computed on national } \\
\text { equivalised household income distributions of respondents in } \\
\text { January 2020). Poverty lines in columns } 2 \text { and } 4 \text { are expressed in } \\
\text { euros per month, without any PPP conversion. }\end{array}$} \\
\hline
\end{tabular}


Table 3: Poverty across countries and interview dates (COME-HERE poverty lines)

\begin{tabular}{lcccc}
\hline & $\begin{array}{c}\text { Mean gap } \\
\text { among poor }\end{array}$ & FGT(0) & $\begin{array}{c}F G T(1) \\
(\times 10)\end{array}$ & $\begin{array}{c}F G T(2) \\
(\times 100)\end{array}$ \\
\hline Jan 2020 & & & & \\
All countries & 504.33 & 0.18 & 0.68 & 3.55 \\
France & 477.60 & 0.17 & 0.56 & 2.70 \\
Germany & 481.65 & 0.14 & 0.47 & 2.39 \\
Italy & 453.67 & 0.21 & 0.80 & 4.17 \\
Spain & 551.12 & 0.20 & 0.84 & 4.53 \\
Sweden & 757.24 & 0.13 & 0.66 & 3.86 \\
\hline May 2020 & & & & \\
All countries & 518.85 & 0.22 & 0.88 & 4.63 \\
France & 509.08 & 0.18 & 0.66 & 3.32 \\
Germany & 476.59 & 0.17 & 0.56 & 2.79 \\
Italy & 488.55 & 0.29 & 1.17 & 6.27 \\
Spain & 563.07 & 0.24 & 1.06 & 5.69 \\
Sweden & 632.98 & 0.19 & 0.80 & 4.32 \\
\hline Sept 2020 & & & & \\
All countries & 492.20 & 0.19 & 0.72 & 3.71 \\
France & 455.43 & 0.17 & 0.54 & 2.44 \\
Germany & 504.27 & 0.16 & 0.56 & 2.87 \\
Italy & 473.95 & 0.24 & 0.96 & 5.13 \\
Spain & 507.87 & 0.20 & 0.81 & 4.15 \\
Sweden & 639.92 & 0.15 & 0.63 & 3.52 \\
\hline Nos Figurare &
\end{tabular}

Notes. Figures are based on equivalised household disposable income and country-specific COME-HERE poverty lines, for the 4,078 respondents in the analysis sample (column 4 of Table 2 ). The mean poverty gap among the poor is expressed in 2019 USD. 


\section{Appendix: Other Figures and Tables}

Figure A1: Relative TIP curves by country, interview date, and age (excluding individuals above age 65)
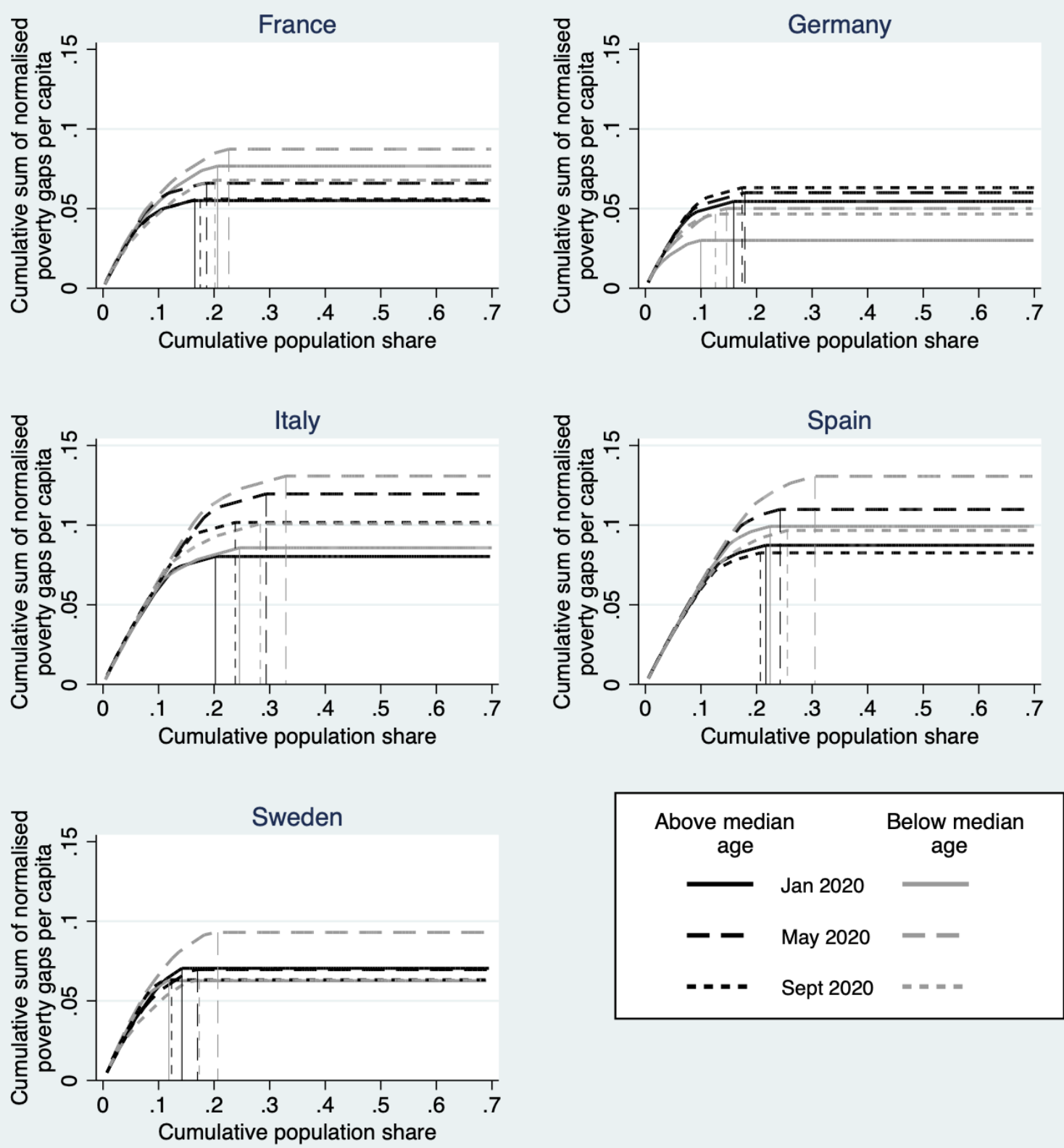

Notes. The figure is based on equivalised household income distributions by country, and country-specific poverty lines, computed as $60 \%$ of the median equivalised income distribution in January 2020 . The points where TIP curves become flat are projected on the $\mathrm{x}$ axis, to indicate the value of $F G T(0)$. 
Figure A2: Relative TIP curves by country, interview date, and employment status in January 2020 (excluding individuals above age 65)
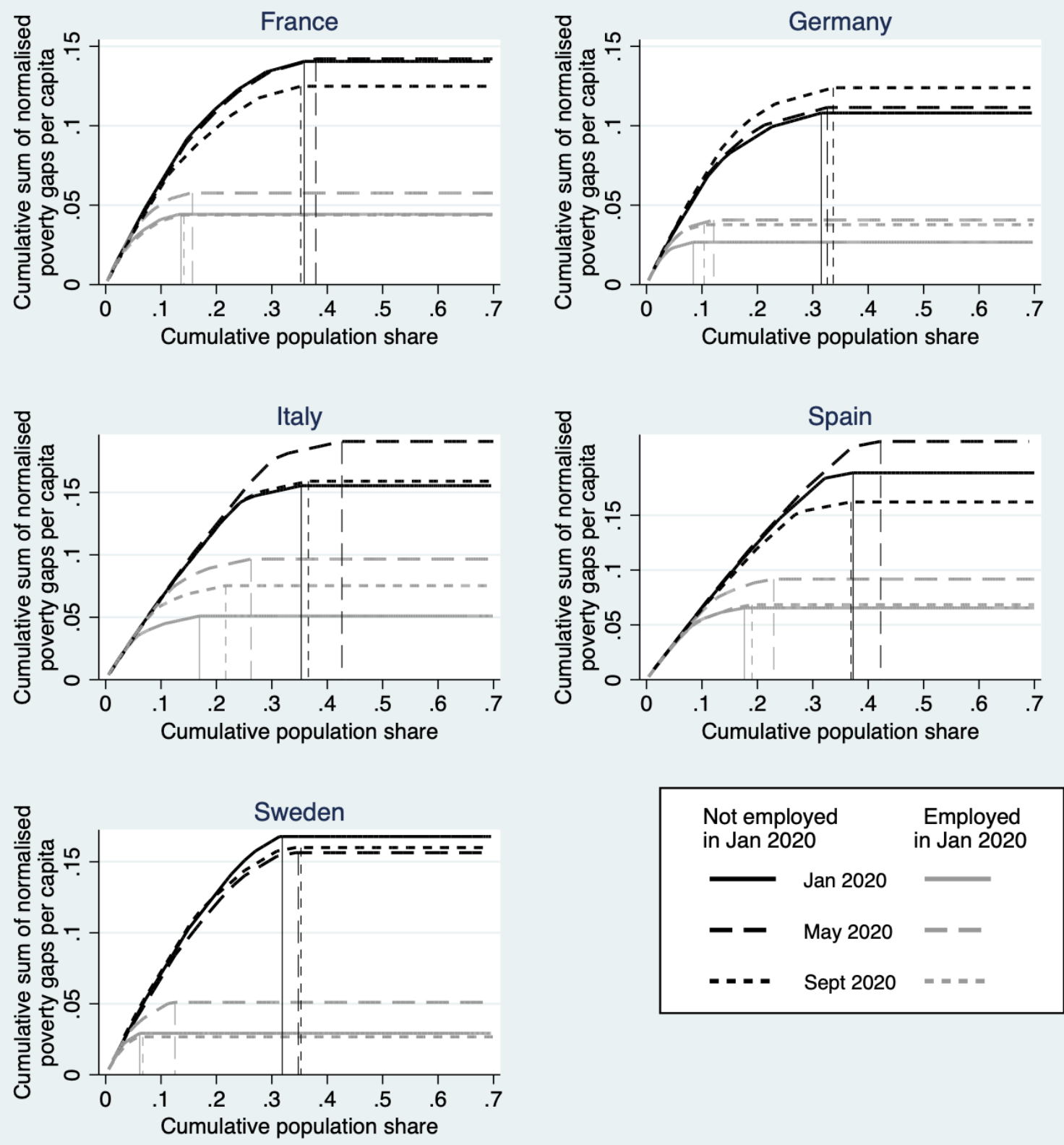

Notes. The figure is based on equivalised household income distributions by country, and country-specific poverty lines, computed as $60 \%$ of the median equivalised income distribution in January 2020 . The points where TIP curves become flat are projected on the $\mathrm{x}$ axis, to indicate the value of $F G T(0)$. 
Table A1: Selection in the analysis sample (W1): differences in means

\begin{tabular}{|c|c|c|c|}
\hline & $\begin{array}{l}\text { Analysis } \\
\text { sample } \\
(1)\end{array}$ & $\begin{array}{l}\text { Rest of W1 } \\
\text { respondents } \\
\text { (2) }\end{array}$ & $\begin{array}{c}(1)-(2) \\
(3)\end{array}$ \\
\hline \multirow[t]{2}{*}{ Equivalised income (PPP) } & 2570.22 & 2542.01 & 28.22 \\
\hline & 1775.77 & 2037.90 & 26.53 \\
\hline \multirow[t]{2}{*}{ At-risk-of-poverty } & 0.178 & 0.235 & $-0.058^{* * *}$ \\
\hline & 0.382 & 0.424 & 0.006 \\
\hline \multirow[t]{2}{*}{ Household size } & 3.629 & 3.697 & $-0.069^{* * *}$ \\
\hline & 1.503 & 1.629 & 0.020 \\
\hline \multirow[t]{2}{*}{ Age } & 49.495 & 42.816 & $6.679^{* * *}$ \\
\hline & 14.582 & 17.293 & 0.209 \\
\hline \multirow[t]{2}{*}{ Female } & 0.483 & 0.558 & $-0.075^{* * *}$ \\
\hline & 0.500 & 0.497 & 0.006 \\
\hline \multirow[t]{2}{*}{ Cohabiting } & 0.717 & 0.602 & $0.114^{* * *}$ \\
\hline & 0.451 & 0.489 & 0.006 \\
\hline \multirow[t]{2}{*}{ Primary education } & 0.189 & 0.190 & -0.001 \\
\hline & 0.392 & 0.392 & 0.005 \\
\hline \multirow[t]{2}{*}{ Secondary education } & 0.367 & 0.441 & $-0.075^{* * *}$ \\
\hline & 0.482 & 0.497 & 0.006 \\
\hline \multirow[t]{2}{*}{ Tertiary education } & 0.444 & 0.369 & $0.075^{* * *}$ \\
\hline & 0.497 & 0.483 & 0.006 \\
\hline \multirow[t]{2}{*}{ Employed in January 2020} & 0.618 & 0.528 & $0.090^{* * *}$ \\
\hline & 0.486 & 0.499 & 0.006 \\
\hline \multirow[t]{2}{*}{ Resident in France } & 0.232 & 0.182 & $0.050^{* * *}$ \\
\hline & 0.422 & 0.386 & 0.005 \\
\hline \multirow[t]{2}{*}{ Resident in Germany } & 0.199 & 0.202 & -0.003 \\
\hline & 0.399 & 0.402 & 0.005 \\
\hline \multirow[t]{2}{*}{ Resident in Italy } & 0.255 & 0.205 & $0.050^{* * *}$ \\
\hline & 0.436 & 0.404 & 0.005 \\
\hline \multirow[t]{2}{*}{ Resident in Spain } & 0.250 & 0.187 & $0.063^{* * *}$ \\
\hline & 0.433 & 0.390 & 0.005 \\
\hline \multirow[t]{2}{*}{ Resident in Sweden } & 0.064 & 0.224 & $-0.161^{* * *}$ \\
\hline & 0.244 & 0.417 & 0.004 \\
\hline Observations & 4,078 & 3,985 & \\
\hline
\end{tabular}

Notes. Odd lines display household-size-weighted averages in columns 1 and 2, and differences in means in column 3. Even lines report standard deviations in columns 1 and 2 , and standard errors in column 3. Stars are for standard significance levels: ${ }^{* * *} \mathrm{p}<0.01$, ${ }^{* *} \mathrm{p}<0.05,{ }^{*} \mathrm{p}<0.1$. W1 indicates wave 1 , taking place in April 2020. Other than equivalised income, at-risk-of-poverty, and employment status (which are either retrospectively collected or inferred from questions referring to January 2020), all other characteristics refer to April 2020 and are here assumed to be time-invariant. 
Table A2: Poverty across countries and interview dates (unique COME-HERE poverty line)

\begin{tabular}{lcccc}
\hline & $\begin{array}{c}\text { Mean gap } \\
\text { among poor }\end{array}$ & FGT(0) & $\begin{array}{c}F G T(1) \\
(\times 10)\end{array}$ & $\begin{array}{c}F G T(2) \\
(\times 100)\end{array}$ \\
\hline Jan 2020 & & & & \\
All countries & 451.83 & 0.22 & 0.73 & 3.73 \\
France & 407.50 & 0.16 & 0.50 & 2.39 \\
Germany & 412.85 & 0.14 & 0.43 & 2.16 \\
Italy & 458.11 & 0.30 & 1.02 & 5.17 \\
Spain & 465.97 & 0.26 & 0.91 & 4.88 \\
Sweden & 616.43 & 0.13 & 0.59 & 3.28 \\
\hline May 2020 & & & & \\
All countries & 475.04 & 0.26 & 0.93 & 4.91 \\
France & 438.78 & 0.18 & 0.59 & 2.97 \\
Germany & 407.79 & 0.17 & 0.50 & 2.53 \\
Italy & 507.88 & 0.38 & 1.44 & 7.64 \\
Spain & 472.31 & 0.32 & 1.14 & 6.14 \\
Sweden & 546.12 & 0.17 & 0.69 & 3.60 \\
\hline Sept 2020 & & & & \\
All countries & 443.84 & 0.23 & 0.77 & 3.93 \\
France & 384.90 & 0.16 & 0.47 & 2.13 \\
Germany & 435.47 & 0.16 & 0.51 & 2.61 \\
Italy & 492.25 & 0.33 & 1.20 & 6.27 \\
Spain & 407.86 & 0.29 & 0.89 & 4.52 \\
Sweden & 581.05 & 0.13 & 0.55 & 2.96 \\
\hline Nes Figts
\end{tabular}

Notes. Figures are based on equivalised household disposable income of individuals in the analysis sample and a unique COME-HERE poverty line, based on January 2020 incomes from all 4,078 respondents. The mean poverty gap among the poor is expressed in 2019 USD. 
Table A3: At-risk-of-poverty rates by NUTS 1 areas and time

\begin{tabular}{|c|c|c|c|}
\hline & January & May & September \\
\hline \multicolumn{4}{|l|}{ France } \\
\hline Île de France & 0.25 & 0.20 & 0.21 \\
\hline Bassin Parisien & 0.16 & 0.20 & 0.19 \\
\hline Nord - Pas-de-Calais & 0.15 & 0.14 & 0.12 \\
\hline Est & 0.31 & 0.37 & 0.30 \\
\hline Ouest & 0.20 & 0.23 & 0.22 \\
\hline Sud-Ouest & 0.14 & 0.15 & 0.13 \\
\hline Centre-Est & 0.16 & 0.15 & 0.15 \\
\hline Méditerranée & 0.07 & 0.14 & 0.10 \\
\hline \multicolumn{4}{|l|}{ Germany } \\
\hline Baden-Wüttemberg & 0.13 & 0.13 & 0.16 \\
\hline Bayern & 0.08 & 0.10 & 0.09 \\
\hline Berlin & 0.11 & 0.11 & 0.11 \\
\hline Brandenburg & 0.33 & 0.27 & 0.27 \\
\hline Bremen & 0.06 & 0.12 & 0.06 \\
\hline Hamburg & 0.12 & 0.20 & 0.17 \\
\hline Hessen & 0.10 & 0.17 & 0.16 \\
\hline Mecklenburg-Vorpommern & 0.38 & 0.38 & 0.44 \\
\hline Niedersachsen & 0.13 & 0.12 & 0.12 \\
\hline Nordrhein-Westfalen & 0.13 & 0.18 & 0.14 \\
\hline Rheinland-Pfalz & 0.08 & 0.19 & 0.15 \\
\hline Saarland & 0.20 & 0.20 & 0.20 \\
\hline Sachsen & 0.24 & 0.21 & 0.23 \\
\hline Sachsen-Anhalt & 0.19 & 0.23 & 0.23 \\
\hline Schleswig-Holstein & 0.12 & 0.12 & 0.11 \\
\hline Thüringen & 0.21 & 0.28 & 0.30 \\
\hline \multicolumn{4}{|l|}{ Italy } \\
\hline Nord-Ovest & 0.15 & 0.28 & 0.21 \\
\hline Nord-Est & 0.23 & 0.29 & 0.26 \\
\hline Centro (I) & 0.14 & 0.21 & 0.17 \\
\hline Sud & 0.19 & 0.24 & 0.22 \\
\hline Isole & 0.31 & 0.39 & 0.33 \\
\hline \multicolumn{4}{|l|}{ Spain } \\
\hline Noroeste & 0.29 & 0.39 & 0.30 \\
\hline Noreste & 0.23 & 0.29 & 0.21 \\
\hline Comunidad de Madrid & 0.11 & 0.16 & 0.16 \\
\hline Centro (E) & 0.18 & 0.19 & 0.17 \\
\hline Este & 0.19 & 0.22 & 0.17 \\
\hline Sur & 0.18 & 0.25 & 0.22 \\
\hline Canarias & 0.23 & 0.30 & 0.26 \\
\hline \multicolumn{4}{|l|}{ Sweden } \\
\hline Östra Sverige & 0.11 & 0.17 & 0.07 \\
\hline Södra Sverige & 0.23 & 0.23 & 0.27 \\
\hline Norra Sverige & 0.11 & 0.19 & 0.17 \\
\hline
\end{tabular}

Notes. Figures are based on equivalised household disposable income of individuals in the analysis sample and country-specific specific COME-HERE poverty lines, for the 4,078 respondents in the analysis sample (column 4 of Table 2). 
Table A4: At-risk-of-poverty thresholds by country and household type

\begin{tabular}{lcccc}
\hline & $(1)$ & $(2)$ & $(3)$ & $(4)$ \\
\hline France & 1128.08 & 1541.69 & 1955.31 & 2368.92 \\
Germany & 1175.75 & 1606.83 & 2037.92 & 2469.00 \\
Italy & 858.25 & 1174.44 & 1490.64 & 1806.83 \\
Spain & 750.75 & 1026.03 & 1301.30 & 1576.58 \\
Sweden & 1223.67 & 1672.36 & 2121.06 & 2569.75 \\
\hline
\end{tabular}

Notes. Poverty lines are expressed in euros per month. Columns 1 and 4 reports atrisk-of-poverty thresholds from Eurostat for year 2019 for a one-person household and a two-adults two-children household, respectively. Columns 2 and 3 report results from a linear interpolation of the Eurostat poverty lines and are meant to represent atrisk-of-poverty thresholds for a two- and a three-persons household, respectively.

Table A5: Poverty across countries and interview dates (Eurostat poverty lines)

\begin{tabular}{lcccc}
\hline & $\begin{array}{c}\text { Mean gap } \\
\text { among poor }\end{array}$ & FGT(0) & $\begin{array}{c}F G T(1) \\
(\times 10)\end{array}$ & $\begin{array}{c}F G T(2) \\
(\times 100)\end{array}$ \\
\hline Jan 2020 & & & & \\
All countries & 536.34 & 0.21 & 0.79 & 4.08 \\
France & 604.51 & 0.18 & 0.69 & 3.46 \\
Germany & 613.03 & 0.17 & 0.62 & 3.20 \\
Italy & 457.11 & 0.30 & 1.02 & 5.12 \\
Spain & 520.32 & 0.19 & 0.81 & 4.28 \\
Sweden & 671.22 & 0.16 & 0.70 & 4.05 \\
\hline May 2020 & & & & \\
All countries & 560.91 & 0.25 & 1.01 & 5.29 \\
France & 652.13 & 0.19 & 0.79 & 4.15 \\
Germany & 625.64 & 0.19 & 0.73 & 3.78 \\
Italy & 505.85 & 0.38 & 1.44 & 7.59 \\
Spain & 530.27 & 0.24 & 1.02 & 5.38 \\
Sweden & 601.99 & 0.22 & 0.85 & 4.59 \\
\hline Sept 2020 & & & & \\
All countries & 536.80 & 0.22 & 0.84 & 4.30 \\
France & 587.54 & 0.18 & 0.67 & 3.20 \\
Germany & 653.30 & 0.18 & 0.72 & 3.81 \\
Italy & 490.73 & 0.33 & 1.20 & 6.22 \\
Spain & 475.25 & 0.20 & 0.77 & 3.90 \\
Sweden & 591.85 & 0.18 & 0.68 & 3.72 \\
\hline Nos Figur
\end{tabular}

Notes. Figures are based on equivalised household disposable income of individuals in the analysis sample and country-specific EU-SILC poverty lines for year 2019, obtained from Eurostat (as displayed in Table A4). The mean poverty gap among the poor is expressed in 2019 USD. 
Table A6: Subgroup decomposition of poverty measures in France

\begin{tabular}{lccccc}
\hline & $\begin{array}{c}\text { Population } \\
\text { share }\end{array}$ & $\begin{array}{c}\text { Mean gap } \\
\text { among poor }\end{array}$ & FGT(0) & $\begin{array}{c}F G T(1) \\
(\times 10)\end{array}$ & $\begin{array}{c}F G T(2) \\
(\times 100)\end{array}$ \\
\hline January 2020 & & & & & \\
Male & 0.51 & 475.52 & 0.13 & 0.43 & 2.09 \\
Female & 0.49 & 478.94 & 0.21 & 0.70 & 3.35 \\
Above median age & 0.48 & 374.05 & 0.14 & 0.37 & 1.57 \\
Below median age & 0.52 & 546.13 & 0.19 & 0.74 & 3.74 \\
Not employed in Jan 2020 & 0.38 & 487.41 & 0.22 & 0.75 & 3.67 \\
Employed in Jan 2020 & 0.62 & 467.74 & 0.14 & 0.45 & 2.11 \\
Primary education & 0.30 & 517.49 & 0.25 & 0.90 & 4.68 \\
At least secondary education & 0.70 & 444.99 & 0.13 & 0.41 & 1.85 \\
\hline May 2020 & & & & & \\
Male & 0.51 & 506.02 & 0.14 & 0.49 & 2.47 \\
Female & 0.49 & 510.94 & 0.23 & 0.84 & 4.21 \\
Above median age & 0.48 & 409.24 & 0.15 & 0.43 & 2.01 \\
Below median age & 0.52 & 572.88 & 0.21 & 0.87 & 4.53 \\
Not employed in Jan 2020 & 0.38 & 484.37 & 0.22 & 0.77 & 3.69 \\
Employed in Jan 2020 & 0.62 & 530.98 & 0.16 & 0.59 & 3.09 \\
Primary education & 0.30 & 542.64 & 0.26 & 1.00 & 5.33 \\
At least secondary education & 0.70 & 483.68 & 0.15 & 0.51 & 2.45 \\
\hline September 2020 & & & & & \\
Male & 0.51 & 399.91 & 0.13 & 0.37 & 1.50 \\
Female & 0.49 & 492.18 & 0.21 & 0.71 & 3.42 \\
Above median age & 0.48 & 397.06 & 0.14 & 0.39 & 1.77 \\
Below median age & 0.52 & 494.76 & 0.19 & 0.67 & 3.05 \\
Not employed in Jan 2020 & 0.38 & 458.71 & 0.21 & 0.67 & 3.04 \\
Employed in Jan 2020 & 0.62 & 452.48 & 0.14 & 0.46 & 2.07 \\
Not cohabiting in wave 1 & 0.23 & 555.71 & 0.32 & 1.26 & 6.31 \\
Cohabiting in wave 1 & 0.77 & 375.59 & 0.12 & 0.32 & 1.28 \\
Primary education & 0.30 & 468.23 & 0.24 & 0.79 & 3.80 \\
At least secondary education & 0.70 & 445.59 & 0.14 & 0.43 & 1.85 \\
\hline
\end{tabular}

Notes. The table shows subgroup decomposition of poverty measures by gender, age (median age is 51 years old), employment status in January 2020, and education. Figures are based on equivalised household disposable income of individuals in the analysis sample and country-specific specific COME-HERE poverty lines, for the 4,078 respondents in the analysis sample (column 4 of Table 2). 
Table A7: Subgroup decomposition of poverty measures in Germany

\begin{tabular}{|c|c|c|c|c|c|}
\hline & $\begin{array}{l}\text { Population } \\
\text { share }\end{array}$ & $\begin{array}{c}\text { Mean gap } \\
\text { among poor }\end{array}$ & $F G T(0)$ & $\begin{array}{c}F G T(1) \\
(\times 10)\end{array}$ & $\begin{array}{c}F G T(2) \\
(\times 100)\end{array}$ \\
\hline \multicolumn{6}{|l|}{ January 2020} \\
\hline Male & 0.54 & 431.02 & 0.12 & 0.36 & 1.65 \\
\hline Female & 0.46 & 524.41 & 0.16 & 0.61 & 3.25 \\
\hline Above median age & 0.56 & 492.80 & 0.17 & 0.59 & 3.03 \\
\hline Below median age & 0.44 & 458.20 & 0.10 & 0.33 & 1.57 \\
\hline Not employed in Jan 2020 & 0.38 & 502.18 & 0.23 & 0.81 & 4.16 \\
\hline Employed in Jan 2020 & 0.62 & 446.77 & 0.08 & 0.26 & 1.28 \\
\hline Primary education & 0.17 & 440.98 & 0.20 & 0.64 & 2.97 \\
\hline At least secondary education & 0.83 & 495.65 & 0.12 & 0.44 & 2.26 \\
\hline \multicolumn{6}{|l|}{ May 2020} \\
\hline Male & 0.54 & 430.31 & 0.14 & 0.43 & 1.96 \\
\hline Female & 0.46 & 515.15 & 0.20 & 0.72 & 3.77 \\
\hline Above median age & 0.56 & 460.48 & 0.19 & 0.61 & 3.12 \\
\hline Below median age & 0.44 & 504.16 & 0.14 & 0.49 & 2.38 \\
\hline Not employed in Jan 2020 & 0.38 & 482.32 & 0.24 & 0.81 & 4.16 \\
\hline Employed in Jan 2020 & 0.62 & 469.57 & 0.12 & 0.40 & 1.94 \\
\hline Primary education & 0.17 & 493.20 & 0.23 & 0.82 & 3.96 \\
\hline At least secondary education & 0.83 & 471.19 & 0.15 & 0.50 & 2.55 \\
\hline \multicolumn{6}{|l|}{ September 2020} \\
\hline Male & 0.54 & 453.07 & 0.12 & 0.39 & 1.85 \\
\hline Female & 0.46 & 541.90 & 0.19 & 0.75 & 4.06 \\
\hline Above median age & 0.56 & 487.28 & 0.18 & 0.61 & 3.11 \\
\hline Below median age & 0.44 & 533.55 & 0.13 & 0.49 & 2.57 \\
\hline Not employed in Jan 2020 & 0.38 & 506.10 & 0.24 & 0.86 & 4.48 \\
\hline Employed in Jan 2020 & 0.62 & 501.65 & 0.10 & 0.37 & 1.86 \\
\hline Primary education & 0.17 & 476.48 & 0.25 & 0.84 & 3.94 \\
\hline At least secondary education & 0.83 & 514.87 & 0.14 & 0.50 & 2.64 \\
\hline
\end{tabular}

Notes. The table shows subgroup decomposition of poverty measures by gender, age (median age is 51 years old), employment status in January 2020, and education. Figures are based on equivalised household disposable income of individuals in the analysis sample and country-specific specific COME-HERE poverty lines, for the 4,078 respondents in the analysis sample (column 4 of Table 2). 
Table A8: Subgroup decomposition of poverty measures in Italy

\begin{tabular}{lccccc}
\hline & $\begin{array}{c}\text { Population } \\
\text { share }\end{array}$ & $\begin{array}{c}\text { Mean gap } \\
\text { among poor }\end{array}$ & FGT(0) & $\begin{array}{c}F G T(1) \\
(\times 10)\end{array}$ & $\begin{array}{c}F G T(2) \\
(\times 100)\end{array}$ \\
\hline January 2020 & & & & & \\
Male & 0.50 & 388.06 & 0.16 & 0.52 & 2.53 \\
Female & 0.50 & 493.71 & 0.26 & 1.08 & 5.81 \\
Above median age & 0.39 & 550.79 & 0.18 & 0.83 & 4.49 \\
Below median age & 0.61 & 405.55 & 0.23 & 0.78 & 3.97 \\
Not employed in Jan 2020 & 0.42 & 532.21 & 0.27 & 1.20 & 6.56 \\
Employed in Jan 2020 & 0.58 & 363.97 & 0.17 & 0.51 & 2.48 \\
Primary education & 0.15 & 536.10 & 0.29 & 1.30 & 6.77 \\
At least secondary education & 0.85 & 431.40 & 0.20 & 0.71 & 3.70 \\
\hline May 2020 & & & & & \\
Male & 0.50 & 409.59 & 0.22 & 0.76 & 3.69 \\
Female & 0.50 & 537.90 & 0.35 & 1.58 & 8.84 \\
Above median age & 0.39 & 554.15 & 0.23 & 1.04 & 5.64 \\
Below median age & 0.61 & 459.71 & 0.33 & 1.25 & 6.68 \\
Not employed in Jan 2020 & 0.42 & 540.96 & 0.33 & 1.47 & 8.08 \\
Employed in Jan 2020 & 0.58 & 441.76 & 0.26 & 0.96 & 4.99 \\
Primary education & 0.15 & 525.92 & 0.39 & 1.73 & 8.95 \\
At least secondary education & 0.85 & 478.46 & 0.27 & 1.07 & 5.78 \\
\hline September 2020 & & & & & \\
Male & 0.50 & 449.89 & 0.18 & 0.69 & 3.61 \\
Female & 0.50 & 488.46 & 0.30 & 1.24 & 6.63 \\
Above median age & 0.39 & 548.53 & 0.20 & 0.90 & 4.83 \\
Below median age & 0.61 & 439.92 & 0.27 & 1.01 & 5.31 \\
Not employed in Jan 2020 & 0.42 & 533.27 & 0.28 & 1.25 & 6.77 \\
Employed in Jan 2020 & 0.58 & 419.49 & 0.22 & 0.76 & 3.95 \\
Primary education & 0.15 & 548.29 & 0.33 & 1.49 & 7.81 \\
At least secondary education & 0.85 & 454.59 & 0.23 & 0.87 & 4.63 \\
\hline N
\end{tabular}

Notes. The table shows subgroup decomposition of poverty measures by gender, age (median age is 51 years old), employment status in January 2020, and education. Figures are based on equivalised household disposable income of individuals in the analysis sample and country-specific specific COME-HERE poverty lines, for the 4,078 respondents in the analysis sample (column 4 of Table 2). 
Table A9: Subgroup decomposition of poverty measures in Spain

\begin{tabular}{lccccc}
\hline & $\begin{array}{c}\text { Population } \\
\text { share }\end{array}$ & $\begin{array}{c}\text { Mean gap } \\
\text { among poor }\end{array}$ & FGT(0) & $\begin{array}{c}F G T(1) \\
(\times 10)\end{array}$ & $\begin{array}{c}F G T(2) \\
(\times 100)\end{array}$ \\
\hline January 2020 & & & & & \\
Male & 0.51 & 571.15 & 0.13 & 0.56 & 3.03 \\
Female & 0.49 & 541.30 & 0.27 & 1.14 & 6.12 \\
Above median age & 0.46 & 571.07 & 0.16 & 0.71 & 3.81 \\
Below median age & 0.54 & 539.00 & 0.23 & 0.96 & 5.15 \\
Not employed in Jan 2020 & 0.37 & 637.56 & 0.24 & 1.17 & 6.57 \\
Employed in Jan 2020 & 0.63 & 481.12 & 0.17 & 0.65 & 3.32 \\
Primary education & 0.14 & 609.61 & 0.39 & 1.85 & 10.45 \\
At least secondary education & 0.86 & 527.44 & 0.16 & 0.67 & 3.52 \\
\hline May 2020 & & & & & \\
Male & 0.51 & 555.55 & 0.16 & 0.71 & 3.74 \\
Female & 0.49 & 567.11 & 0.32 & 1.43 & 7.76 \\
Above median age & 0.46 & 546.08 & 0.17 & 0.72 & 3.76 \\
Below median age & 0.54 & 571.35 & 0.30 & 1.35 & 7.36 \\
Not employed in Jan 2020 & 0.37 & 625.81 & 0.27 & 1.30 & 7.20 \\
Employed in Jan 2020 & 0.63 & 519.38 & 0.23 & 0.91 & 4.80 \\
Primary education & 0.14 & 620.06 & 0.41 & 1.97 & 11.30 \\
At least secondary education & 0.86 & 544.55 & 0.21 & 0.90 & 4.74 \\
\hline September 2020 & & & & & \\
Male & 0.51 & 524.07 & 0.14 & 0.56 & 2.82 \\
Female & 0.49 & 499.45 & 0.28 & 1.08 & 5.56 \\
Above median age & 0.46 & 533.97 & 0.16 & 0.65 & 3.36 \\
Below median age & 0.54 & 493.41 & 0.25 & 0.95 & 4.85 \\
Not employed in Jan 2020 & 0.37 & 563.00 & 0.24 & 1.04 & 5.51 \\
Employed in Jan 2020 & 0.63 & 466.65 & 0.19 & 0.68 & 3.36 \\
Primary education & 0.14 & 592.12 & 0.36 & 1.65 & 9.08 \\
At least secondary education & 0.86 & 479.36 & 0.18 & 0.67 & 3.32 \\
\hline
\end{tabular}

Notes. The table shows subgroup decomposition of poverty measures by gender, age (median age is 51 years old), employment status in January 2020, and education. Figures are based on equivalised household disposable income of individuals in the analysis sample and country-specific specific COME-HERE poverty lines, for the 4,078 respondents in the analysis sample (column 4 of Table 2). 
Table A10: Subgroup decomposition of poverty measures in Sweden

\begin{tabular}{|c|c|c|c|c|c|}
\hline & $\begin{array}{l}\text { Population } \\
\text { share }\end{array}$ & $\begin{array}{l}\text { Mean gap } \\
\text { among poor }\end{array}$ & $F G T(0)$ & $\begin{array}{c}F G T(1) \\
(\times 10)\end{array}$ & $\begin{array}{c}F G T(2) \\
(\times 100)\end{array}$ \\
\hline \multicolumn{6}{|l|}{ January 2020} \\
\hline Male & 0.56 & 699.60 & 0.09 & 0.43 & 2.39 \\
\hline Female & 0.44 & 794.09 & 0.18 & 0.97 & 5.74 \\
\hline Above median age & 0.36 & 789.69 & 0.14 & 0.77 & 4.54 \\
\hline Below median age & 0.64 & 735.61 & 0.12 & 0.61 & 3.47 \\
\hline Not employed in Jan 2020 & 0.28 & 783.81 & 0.31 & 1.62 & 9.54 \\
\hline Employed in Jan 2020 & 0.72 & 705.66 & 0.06 & 0.29 & 1.65 \\
\hline Primary education & 0.13 & 737.86 & 0.15 & 0.74 & 4.38 \\
\hline At least secondary education & 0.87 & 760.66 & 0.13 & 0.65 & 3.78 \\
\hline \multicolumn{6}{|l|}{ May 2020} \\
\hline Male & 0.56 & 589.41 & 0.17 & 0.68 & 3.38 \\
\hline Female & 0.44 & 679.03 & 0.21 & 0.95 & 5.53 \\
\hline Above median age & 0.36 & 686.35 & 0.17 & 0.77 & 4.18 \\
\hline Below median age & 0.64 & 607.92 & 0.20 & 0.82 & 4.41 \\
\hline Not employed in Jan 2020 & 0.28 & 656.89 & 0.35 & 1.55 & 8.36 \\
\hline Employed in Jan 2020 & 0.72 & 606.98 & 0.13 & 0.51 & 2.76 \\
\hline Primary education & 0.13 & 654.94 & 0.23 & 1.00 & 5.51 \\
\hline At least secondary education & 0.87 & 628.80 & 0.18 & 0.77 & 4.14 \\
\hline \multicolumn{6}{|l|}{ September 2020} \\
\hline Male & 0.56 & 595.00 & 0.11 & 0.44 & 2.32 \\
\hline Female & 0.44 & 671.91 & 0.20 & 0.89 & 5.07 \\
\hline Above median age & 0.36 & 758.51 & 0.14 & 0.74 & 4.30 \\
\hline Below median age & 0.64 & 574.94 & 0.15 & 0.58 & 3.08 \\
\hline Not employed in Jan 2020 & 0.28 & 662.97 & 0.36 & 1.58 & 9.06 \\
\hline Employed in Jan 2020 & 0.72 & 592.59 & 0.07 & 0.27 & 1.37 \\
\hline Primary education & 0.13 & 770.57 & 0.26 & 1.33 & 7.92 \\
\hline At least secondary education & 0.87 & 600.88 & 0.13 & 0.53 & 2.85 \\
\hline
\end{tabular}

Notes. The table shows subgroup decomposition of poverty measures by gender, age (median age is 51 years old), employment status in January 2020, and education. Figures are based on equivalised household disposable income of individuals in the analysis sample and country-specific specific COME-HERE poverty lines, for the 4,078 respondents in the analysis sample (column 4 of Table 2). 
Table A11: Poverty across countries and interview dates (COME-HERE poverty lines)

\begin{tabular}{lcccc}
\hline & $\begin{array}{c}\text { Mean gap } \\
\text { among poor }\end{array}$ & FGT(0) & $\begin{array}{c}F G T(1) \\
(\times 10)\end{array}$ & $\begin{array}{c}F G T(2) \\
(\times 100)\end{array}$ \\
\hline Jan 2020 & & & & \\
All countries & 512.06 & 0.18 & 0.72 & 3.76 \\
France & 477.03 & 0.18 & 0.59 & 2.84 \\
Germany & 488.67 & 0.15 & 0.53 & 2.68 \\
Italy & 476.69 & 0.21 & 0.85 & 4.53 \\
Spain & 551.72 & 0.20 & 0.85 & 4.57 \\
Sweden & 766.10 & 0.13 & 0.69 & 4.04 \\
\hline May 2020 & & & & \\
All countries & 524.63 & 0.23 & 0.92 & 4.90 \\
France & 508.14 & 0.19 & 0.69 & 3.52 \\
Germany & 472.21 & 0.18 & 0.62 & 3.03 \\
Italy & 496.95 & 0.29 & 1.21 & 6.54 \\
Spain & 576.34 & 0.25 & 1.11 & 6.01 \\
Sweden & 657.78 & 0.19 & 0.83 & 4.63 \\
\hline Sept 2020 & & & & \\
All countries & 503.17 & 0.20 & 0.78 & 4.03 \\
France & 456.89 & 0.18 & 0.58 & 2.68 \\
Germany & 495.47 & 0.17 & 0.60 & 3.01 \\
Italy & 495.19 & 0.25 & 1.02 & 5.57 \\
Spain & 523.32 & 0.21 & 0.87 & 4.52 \\
Sweden & 677.12 & 0.15 & 0.68 & 3.88 \\
\hline Nos. Figus &
\end{tabular}

Notes. Figures are based on equivalised household disposable income and country-specific COME-HERE poverty lines, for the 4,078 respondents in the analysis sample (column 4 of Table 2). Household size is here measured as reported by respondents. The mean poverty gap among the poor is expressed in 2019 USD. 